\title{
Acute and Subchronic Toxic Effects of Thioridazine versus Pimozide on Liver, Kidney and Heart of Adult Male Albino Rats: Biochemical and Histological Study
}

\author{
Amany Salah Mohammed ${ }^{1}$ and Noha Mohammed Afifi ${ }^{2}$
}

\author{
${ }^{1}$ Forensic Medicine and Clinical Toxicology Department \\ ${ }^{2}$ Histology Department
}

Faculty of Medicine, Cairo University, Cairo, Egypt.

\begin{abstract}
Antipsychotic drugs are potent drugs that therapeutically modify behavior. They are widely used all over the world. This study was planned to compare the biochemical and histological alterations induced by acute and subchronic toxic effects of the typical antipsychotic drugs "Thioridazine (Melleril) and Pimozide (Orap)" on liver, kidney and heart of adult male albino rats.

Animals were divided into two main groups. Group I "Acute Toxicity Group" included 18 rats that were divided equally into 3 subgroups; 6 rats each: subgroup Ia: served as control. Subgroup Ib received a single oral toxic dose of thioridazine $(26.4 \mathrm{mg} / 100 \mathrm{gm} \mathrm{B.W})$ and subgroup Ic received a single oral toxic dose of pimozide (11 mg/100 gm B.W). Group II "Subchronic Toxicity Group" included 30 rats which were divided equally into 5 subgroups; 6 rats each that were given daily doses of the drugs orally for 12 weeks: Subgroup IIa: Served as control. Subgroup IIb received dose equal to $1 / 20$ of $\mathrm{LD}_{50}$ of thioridazine $(5.4 \mathrm{mg} / 100 \mathrm{gm} \mathrm{B} . \mathrm{W})$, Subgroup IIc received dose equal to $1 / 10$ of $\mathrm{LD}_{50}$ of thioridazine $(10.8 \mathrm{mg} / 100 \mathrm{gm}$ B.W). Subgroup IId received dose equal to $1 / 50$ of $\mathrm{LD}_{50}$ of pimozide $(2.2 \mathrm{mg} / 100 \mathrm{gm} \mathrm{B}$.W). Subgroup IIe received dose equal to $1 /{ }_{25}$ of $\mathrm{LD}_{50}$ of pimozide $(4.4 \mathrm{mg} / 100 \mathrm{gm} \mathrm{B} . \mathrm{W})$.

At the end of the experiment, blood samples were taken for biochemical analysis of liver transaminases (serum AST, ALT levels), serum LDH, cholesterol level and kidney function tests (urea, creatinine, and uric acid levels). Sections from the liver, kidney and heart were subjected to H\&E stain (those from liver and heart were also stained with Masson's Trichrome). Mean sinusoidal area in liver sections, mean glomerular area in kidney sections and mean area \% of collagen in ventricular sections. Results were compared statistically.

Results of the acute study revealed significant elevation in liver enzymes and LDH of rats receiving both drugs as well as some morphological alterations in pimozide group.

Biochemical changes in subchronic study showed significant elevation of liver enzymes and LDH in rats receiving both drugs at both doses. Cholesterol level increased significantly only with intake of pimozide (subgroups IId and IIe). Moreover, urea and creatinine levels increased significantly with the intake of the higher toxic dose of each drug (subgroups IIc and IIe). Concerning the histological assessment, lower toxic dose of thioridazine spared the liver and heart while affecting the kidney sections. Using the higher toxic dose of thioridazine as well as both doses of pimozide induced marked morphological alterations in all organs. In conclusion, both drugs tested in the current work proved to have definite toxic effects on the liver, kidney and heart. However, pimozide was more injurious and toxic than thioridazine. Thus, they should be prescribed under restricted conditions and periodic assessment of cardiac, hepatic and renal functions should be done detect early toxic effects.
\end{abstract}

Keywords Thioridazine, pimozide, antipsychotics, toxicity, histology, kidney, liver, heart, urea, creatinine, AST, ALT, LDH, cholesterol

\section{Introduction}

especially in schizophrenia and bipolar disorder, posttraumatic stress disorder, delirium, and personality disorders. Additionally, they are widely used to 
manage non-psychotic disorders against multidrugresistant mycobacterium tuberculosis and methicillinresistant staphylococcus aureus (MRSA) at clinical concentrations (Amaral et al., 2010).

Antipsychotics are divided into two main groups, the "typical, conventional or first-generation" and the "atypical or second-generation antipsychotics". The typical antipsychotics are classified depending on their chemical structure into two main categories; phenothiazines and butyrophenones. Both generations act by blockade of dopamine receptors in the brain and are probably mediated by serotonergic receptors (Challoner, 2005).

First-generation antipsychotics are as effective as second-generation drugs in treating the "positive" symptoms of schizophrenia, such as hallucinations, delusions, and paranoia, although they vary in their propensity to cause side effects. Thioridazine and pimozide are typical antipsychotic drugs belonging to the phenothiazines and diphenylbutylpiperidines groups respectively. Both drugs are commonly used (Lieberman and Tasman, 2006).

Thioridazine is used in the management of psychoses, including schizophrenia and generalized anxiety disorder. Thioridazine blocks postsynaptic dopamine receptors (D1 and D2) in the brain and also blocks the alpha-adrenergic effect. It inhibits the release of hypothalamic and hypophyseal hormones and may depress the reticular activating system with consequent affection of the wakefulness, basal metabolic rate, body temperature, blood pressure and emesis (Milnes et al., 2006).

Therapeutic blood levels of thioridazine range from 140 to $660 \mu \mathrm{g} / \mathrm{L}$ after a single dose of $100 \mathrm{mg}$ by 3 hours. It undergoes extensive hepatic metabolism to active and inactive compounds, secreted in bile and excreted mainly in the faeces. Less than about $10 \%$ of a dose is excreted in the urine, with less than $1 \%$ as unchanged drug (Wang et al., 2005).

Pimozide has neuroleptic properties that found to be beneficial in the management of chronic schizophrenic patients and mania as a short term treatment of moderate to severe agitation and excitement (Kang et al., 2000).

Pimozide is rapidly absorbed after oral administration; peak plasma concentrations occur at between 4 and 8 hours and its plasma half-life is about 6 hours. The drug is highly bound to plasma proteins, especially albumin. It undergoes hepatic metabolism and is eliminated via the kidneys (Wang et al., 2005).

The mechanism of pimozide's action is thought to be related to its selective blockade of the dopaminergic receptors particularly dopamine D2 receptor in the CNS, although it affects norepinephrine at higher doses. The receptor blockade is usually accompanied by secondary alterations in dopamine metabolism and function which may result in both pimozide's therapeutic and unwanted effects (Kang et al., 2001).

The outcome of dopamine receptor antagonist overdose is generally favourable. Neurological adverse effects commonly seen with conventional antipsychotics include extrapyramidal reactions producing symptoms that mimic Parkinson's disease in the form of muscle stiffness, rigidity and tremors (Peluso et al., 2012). Severe symptoms including delirium, coma, respiratory depression and seizures are relatively uncommon (DeRoos, 2001).

There are non-neurological serious adverse effects that might occur from cardiovascular complications like hypotension, tachycardia and ventricular dysrhythmias or conduction delay. Prolonged QT interval (the time required for depolarization and depolarization of the ventricles) was reported in ECG of anti-psychotic users, which might signal a potential for developing arrhythmias (Lieberman and Tasman, 2006). The cardiac effects of dopamine receptor antagonists have been hypothesized to be responsible for sudden death in patients treated with these drugs. However, controversy regarding this issue exists because the introduction of dopamine receptor antagonists had no effect on incidence of sudden death in schizophrenic patients treated with anti-psychotics (Raedler, 2010). It has been reported that overdose of thioridazine can lead to heart block, ventricular fibrillation and death (Sadock and et al., 2004).

Some gastrointestinal adverse effects in the form of anorexia, nausea and/or vomiting, constipation, diarrhea, and abdominal cramps or pain have been observed in some patients receiving pimozide. Obstructive or cholestatic jaundice may develop but it's a rare complication, regarded as a hypersensitivity reaction which might occur in the first few months of treatment. Blood films of patients show eosinophilia. Patients have bilirubin in urine, increased serum bilirubin, alkaline phosphatase and hepatic transaminases (Healy, 2005).

Elimination and excretion of antipsychotic drugs occurs mainly through the kidneys. Therefore, special care should be addressed to patients these medications for long periods, particulary elderly patients where the condition might be aggravated by decreased renal blood flow, impaired tubular function and decreased glomerular filtration (Bouman and Pinner, 2002).

Toxic effects of antipsychotic drugs may be acute or chronic resulting from unintentional or intentional overdose or might result simply following therapeutic administration (Voruganti et al., 2008).

Several factors are implicated in the development of adverse effects or toxicity including prescription and utilization of these drugs by previously institutionalized mental patients as outpatients without supervision (Whitaker, 2004). Moreover, psychotic patients are at greater risk than the general population for suicidal or self-destructive attitude. Tablet preparations resemble smooth coated candies making them attractive to children (Kasckow et al., 2011).

\section{Aim of the work}

This study was planned to compare the biochemical and histological alterations induced by acute and subchronic toxic doses of the antipsychotic drugs 
"thioridazine and pimozide" on the liver, kidney and heart of adult male albino rats.

\section{Materials and methods}

\section{I) Drugs}

\section{1) Thioridazine hydrochloride (Melleril)}

It is manufactured by Novartis Pharmaceuticals Company, Cairo, Egypt, in the form of tablets. Each tablet contains $25 \mathrm{mg}$ of thioridazine HCL.

Thioridazine is a white or slightly yellowish crystalline powder. Its chemical name is $10-(2-\mathrm{Cl}-$ methyl -2 piperidinyl - ethyl)-2-C methyl thiol-10H Phenothiazine, i.e. $\mathrm{C}_{21} \mathrm{H}_{26} \mathrm{~N}_{2} \mathrm{~S}_{2}$, HCL (Moffat et al., 2004).

Each dose of thioridazine was dissolved in 1 $\mathrm{ml}$ distilled water and was supplied to rats by gavage.

\section{2) Pimozide (Orap)}

It is manufactured by: Janssen-Cilag Pharmaceutical Company, Cairo, Egypt, in the form of tablets. Each tablet contains $1 \mathrm{mg}$ pimozide.

Pimozide is a colourless microcrystalline powder. Its chemical name is (1- $(4,4$ Bis (4fluorophenyl) butyl)-piperid-2-one, i.e. $\mathrm{C}_{28} \mathrm{H}_{29} \mathrm{~F}_{2} \mathrm{~N}_{3} \mathrm{O}$ (Moffat et al., 2004).

Each dose of pimozide was dissolved in $1 \mathrm{ml}$ distilled water and was supplied to rats by gavage.

\section{II) Animals used and experimental design}

The present experimental work was carried out on 48 adult male albino rats, 10 weeks old. They were bred in the animal house at Faculty of Medicine, Cairo University, according to the Guidelines for the Care and Use of Laboratory Animals. Their body weights ranged between 120-180 gm with a mean value of $150 \pm 20 \mathrm{gm}$. All rats were weighed twice weekly to modify the doses of the drugs.

Each three rats were housed in a separate hygienic cage measuring $60 \times 30 \times 30 \mathrm{~cm}^{3}$ to avoid stress of isolation or over-crowding. They were kept in an ambient temperature of $25 \pm 2^{\circ} \mathrm{C}$ on a normal light/dark cycle. The heat due to direct sunlight was avoided and the room was illuminated by indirect daylight. The animals were acclimatized to the laboratory conditions for two weeks before the experiment. The rats were fed on balanced rat chew diet and had free access to water. The time of drug administration was fixed for all groups of rats at 10 a.m. daily.

Animals were divided into two main study groups; Group I and Group II:

- Group I [Acute Toxicity Study Group] Included 18 rats which were divided equally into 3 subgroups; 6 rats each:

- Subgroup Ia: Served as control. They received distilled water as a vehicle by gavage.

- Subgroup Ib: Rats received a single oral toxic dose of thioridazine by gavage $(26.4 \mathrm{mg} / 100 \mathrm{gm} \quad \mathrm{B} . \mathrm{W})$ (Challoner, 2005).
- Subgroup Ic: Rats received a single oral toxic dose of pimozide by gavage $(11 \mathrm{mg} / 100 \mathrm{gm} \quad$ B.W $)$ (Challoner, 2005).

- Group II [Subchronic Toxicity Study Group] Included 30 rats which were divided equally into 5 subgroups; 6 rats each:

- Subgroup IIa: Served as control. Rats received distilled water as a vehicle by gavage.

- Subgroup IIb: Rats received doses equal to $1 / 20$ of LD50 of thioridazine $(5.4 \mathrm{mg} / 100 \mathrm{gm} \mathrm{B.W})$ [Lethal dose $=$ 1034-1083 $\mathrm{mg} / \mathrm{kg}$ ] (Moffat et al., 2004).

- Subgroup IIc: Rats received doses equal to $1 / 10$ of LD50 of thioridazine (10.8 mg/100 gm B.W).

- Subgroup IId: Rats received doses equal to $1 / 50$ of LD50 of pimozide $(2.2 \mathrm{mg} / 100 \mathrm{gm} \mathrm{B.W})$ [Lethal dose $=$ $1100 \mathrm{mg} / \mathrm{kg}$ ] (Moffat et al., 2004).

- Subgroup IIe: Rats received doses equal to $1 / 25$ of LD50 of pimozide (4.4 mg/100 gm B.W).

All rats of the five groups were given the drugs daily for continuous 12 weeks by gavage.

\section{Biochemical study}

Blood samples were obtained at the end of the experimental periods from the retro-orbital venous plexus by means of heparinized micro-capillary tubes in dry, clean and sterile test tubes containing heparin as anticoagulant (4-5 IU). Then the samples were centrifuged at 3000 r.p.m for 15 minutes and the clear plasma was separated carefully and stored in screw capped sterile vials at $-20^{\circ} \mathrm{C}$ until analysis.

The following biochemical parameters were measured in the prepared plasma samples:
a. AST (Aspartate transaminase).
b. ALT (Alanine transaminase). $a$ and $b$ were estimated by colourimetric estimation (Bergmeyer, 1986), for analysis of liver functions as biomarkers of liver injury] (Giannini et al., 2005).

c. LDH (lactate dehydrogenase) was estimated according to Weisshaar et al., (1975).

d. Plasma cholesterol was estimated using Bio Merieux Kits (Richmond, 1973).

c and d were estimated for analysis of cardiac functions (Rao et al., 1999).

e. Kidney function tests

1. Determination of serum urea was done according to enzymatic method of Patton and Crouch, (1977). 
2. Determination of serum creatinine was done using Stanbio reagent kits (Faulkner and King, 1976).

3. Determination of serum uric acid was done using Stanbio reagent kits (Caraway, 1955).

\section{Histological study: light microscopic study}

Animals were sacrificed by intraperitoneal injection of $2 \mathrm{ml}$ of pentobarbital (overdose anesthesia) (Leishi et al., 2007). Specimens from the liver, kidneys and heart (samples from the left ventricles) from each animal were immediately dissected, fixed in $10 \%$ formol saline, dehydrated in ascending grades of alcohol, cleared in xylol, then embedded in paraffin in Histology Department, Faculty of Medicine, Cairo University. Sections were serially cut into 5-7 $\mu \mathrm{m}$ thickness using a microtome, mounted on glass slides and subjected to Haematoxylin and Eosin Stain for histological assessment (Kiernan, 2001). Masson's Trichrome stain was used for demonstration of collagen fibers in liver and cardiac muscle sections (Bancroft and Stevens, 1996).

\section{Morphometric study}

Using a Leica Qwin 500 LTD image analysis computer system, Cambridge, UK, the following parameters were measured:

$$
\begin{aligned}
& \text { 1- Mean blood } \\
& \text { sinusoidal area in } \\
& \text { liver sections. }
\end{aligned}
$$

These parameters were measured in 10 random fields for each specimen in the different groups using the interactive measuring menu of the image analyzer at a magnification of $X$ 100. Serial sections were used to measure 100 sinusoids and 100 glomeruli for each specimen and their mean values were obtained.

3- The mean area percentage of the collagen content of myocardial

sections was
measured in Masson's

Trichrome-stained sections in 10 nonoverlapping fields at a magnification of $\times 400$ using color detect menu. The image analyzer was used to measure the area of collagen fiber content and was expressed in an area percentage in relation to the area of the standard measuring frame.

\section{Statistical analysis}

Data obtained were analyzed using SPSS, Windows Version 9, Chicago, USA. Comparison between the values of each two groups was performed using posthoc test. ANOVA (One Way Analysis of Variance) was done to test the significance of difference between more than two groups. P-value was considered significant if less than 0.05 (Armitage and Berry, 1994).

\section{Results}

\section{Analysis of biochemical parameters}

\section{Group I [Acute toxicity study]}

1- Serum transaminases (AST and ALT)

Single toxic dose of both studied drugs (thioridazine and pimozide) resulted in significant elevation of AST and ALT levels, as compared to the control $(\mathrm{P}<0.05)$. However, the elevation was more marked with pimozide than thioridazine as shown in Table (1).

\section{2- LDH and cholesterol serum level}

Single toxic dose of both studied drugs caused increase in both LDH and cholesterol levels as compared with the control value. LDH increments were significant in relation to the control group $(\mathrm{P}<0.05)$ while the cholesterol increase was nonsignificant $(\mathrm{P}>0.05)$ as shown in Table (2).

\section{3- Kidney function tests}

Single toxic dose of both studied drugs caused non-significant increase in urea, creatinine and uric acid as compared with the control $(\mathrm{P}>0.05)$ as shown in Table (3).

\section{Group II [Subchronic toxicity study]}

\section{1- Serum transaminases (AST and ALT)}

There was significant elevation in AST and ALT levels after daily use of thioridazine and pimozide for all subgroups, when compared with the values recorded for the control rats as well as when compared to each other $(\mathrm{P}<0.05)$. The elevation was more evident in rats which received pimozide (subgroups IId and IIe) than in those which received thioridazine (subgroups IIb and IIc) as shown in (Tables 4 and 7).

\section{2- LDH and Cholesterol serum level}

LDH levels were significantly elevated after thioridazine and pimozide administration for 12 weeks for all subgroups, when compared with the control group $(\mathrm{P}<0.05)$. Rats which received pimozide exhibited more increase in LDH levels.

There was no statistically significant increase in serum cholesterol level of rats which received thioridazine (subgroups IIb and IIc). On the other hand, there was significant elevation in cholesterol level in rats which received pimozide in subgroups IId and IIe, 
when compared with control rats and also when compared to each other $(\mathrm{P}<0.05)$ as shown in (Tables 5 and 8).

\section{3- Kidney function tests}

No statistically significant changes in urea, creatinine and uric acid levels were recorded after subchronic administration of the lower doses of either thioridazine (subgroup IIb) or pimozide (subgroup IId) $(\mathrm{P}>0.05)$.

On the other hand, urea and creatinine levels were significantly increased after administration of the higher doses of both thioridazine (subgroup IIc) and pimozide (subgroup IIe). This elevation was higher in subgroup IIe than in subgroup IIc as shown in (Tables 6 and 9).

\section{II) Histological study: light microscopic results (H\&E stain)}

Rats which received a single oral toxic dose of thioridazine showed no morphological abnormalities in all the examined organs.

\section{Liver sections}

Light microscopic examination of H\&E-stained liver sections of the control group showed the normal histological structure of the liver. Central veins were located in the center of hepatic lobules. Hepatocytes were extending in a radial manner from the center towards the periphery of the lobules. They were arranged in the form of hepatic plates. Hepatic plates were separated by blood sinusoids that drained into the central vein (Figure1a).

Portal tracts were demonstrated at the periphery of the lobules comprising four components; the largest of which was a branch of the portal vein having a thin wall and wide lumen with flattened endothelial lining. A branch of the hepatic artery had a thick wall and narrow lumen. Bile duct exhibited cuboidal lining epithelium. A lymph vessel had a very thin wall (Figure1b).

In the acute toxicity study, hepatic sections of rats receiving single oral toxic dose of pimozide revealed congestion of central veins as well as blood sinusoids. Hepatocytes exhibited normal radial arrangement. Mononuclear cellular infiltration was evident in the portal tracts (Figure 1c).

As regards specimens from subchronic toxicity study, H\&E-stained liver sections of subgroup IIb revealed no morphological abnormalities. However, subgroup IIc sections presented with congestion of central veins and hepatic sinusoids accompanied with vacuolar degenerative cytoplasmic changes of the hepatocytes (Figure 1d). Sections of subgroup IId as well as subgroup IIe both showed congestion of portal veins as well as mononuclear cellular infiltration surrounding the portal tracts, in addition to sinusoidal dilatation (Figs.1e and 1f).

Masson's Trichrome-stained control liver sections showed few collagen fibers content surrounding the portal tract and the wall of the blood sinusoids (Figure 1g). Liver sections of other subgroups stained with Masson's Trichrome revealed the presence of collagen fibers in a similar pattern to that of the control. On the other hand, liver sections of subgroup IIe showed marked collagen fiber deposition surrounding the portal tracts (Figure $1 \mathrm{~h}$ ).

\section{Kidney sections}

Examination of kidney sections of control rats showed normal histological structures of the Malpighian renal corpuscles as well as proximal and distal convoluted tubules. (Figs. 2a and 2b).

In the acute toxicity study, kidney sections of rats receiving single oral toxic dose of pimozide revealed dilated congested glomerular blood capillaries and extravasation of RBCs in the renal interstitium. Some of the distal tubules exhibited widened lumina (Figure 2c). On examining kidney sections of subgroup IIb from subchronic toxicity study, distortion of glomerular capillary tufts was noted accompanied by widening of Bowman's space. Glomerular capillaries appeared congested. Extravasation of RBCs in the renal interstitium was noted. Renal tubules appeared apparently normal where most of the tubules exhibited pale vesicular nuclear lining and intact cytoplasm (Figure 2d). H\&E-stained sections of subgroup IIc revealed distorted renal corpuscles with separated glomerular tufts. Epithelial cells lining renal tubules showed cytoplasmic vacuolation and shedding of cells in lumina. In other tubules, cellular debris was dislodged in lumina. Severe congestion of blood vessels and interstitial hemorrhage was encountered (Figure 2e). Sections of subgroup IId showed distortion of glomerular capillaries, widening of Bowman's space, in addition to congestion of glomerular capillary tufts and interstitial hemorrhage (Figure 2f). Lastly, sections of subgroup IIe presented with splitting and congestion of glomerular capillaries. Marked rarefaction of cytoplasm of epithelial tubular cells was noted, in addition to shedding and desquamation of some of the lining epithelial cells inside the tubular lumina. Many pyknotic nuclei of the lining tubular epithelial cells were detected. Tubular brush border was markedly distorted (Figure $2 \mathrm{~g}$ ).

\section{Cardiac muscle sections}

Light microscopic examination of cardiac myocytes in H\&E-stained sections of the control group showed normal histological architecture. The cardiomyocytes appeared as branching, anastmosing cylindrical cells of uniform diameter. Clear striations were evident in sarcoplasm. Adjacent cells were separated by connective tissue containing blood vessels (Figs. 3a and3b).

In the acute toxicity study, cardiac muscle sections of rats receiving single oral toxic dose of pimozide revealed marked dilatation and congestion of blood vessels located inbetween cardiac myocytes. Mucle fibers appeared disorganized (Figure 3c).

As regards specimens from subchronic toxicity study, H\&E-stained cardiac muscle sections of subgroup IIb revealed no detectable morphological abnormalities. On the other hand, H\&E-stained sections of subgroups IIc, IId and IIe revealed disruption of cardiac myocytes which appeared markedly separated. Most of the cardiac myocytes exhibited cytoplasmic degeneration and separation of 
myofibrils, while few fibers had deeply acidophilic sarcoplasm and presented with peripheral nuclei. Severe hemorrhage, as well as accumulation of homogenous acidophilic exudates between the muscle fibers and extravasation of RBCs between the muscle fibers was noted (Figs. 3d, 3e and 3f).

Masson's Trichrome (MT) stained-sections of cardiac muscle of the control group revealed the presence of few collagen fibers in between the cardiac myocytes (Figure 3g). MT-stained sections of all the experimental subgroups showed deposition of collagen fibers close to the control picture. However, subgroup IIe sections showed increased deposition of collagen fibers, compared to the control (Figure $3 \mathrm{~h}$ ).

\section{Morphometric and statistical results}

\section{(I) Mean Sinusoidal Area $(\mu 2)( \pm S D)$ in liver sections of the studied groups}

The mean sinusoidal area did not show a statistically significant difference between the subgroups which received a single acute dose of either drug (Ib\&Ic), as compared to the control, or to each other. However, a statistically significant increase in the sinusoidal area was detected in sections of subgroup IIc [compared to
Ia, Ib and IIb] and subgroup IIe [compared to Ia, Ic and IId] (Table 10, Histogram 1).

\section{(II) Mean Glomerular Area $(\mu 2)( \pm S D)$ in kidney} sections of the studied groups

No statistically significant difference was reported for the mean glomerular area between subgroups Ib\&Ic, as compared to the control, or to each other. However, a statistically significant decrease in the glomerular area was recorded for sections of subgroup IIc [compared to $\mathrm{Ia}, \mathrm{Ib}$ and IIb] as well as subgroup IIe [compared to Ia, Ic and IId] (Table 11, Histogram 2).

(III) Mean area $\%$ of collagen fiber content $( \pm$ SD) in Masson's-Trichrome stained ventricular sections of the studied groups

The mean area \% of collagen fiber content did not show any statistically significant difference between all the subgroups when compared to the control, except subgroup IIe which received the high dose of pimozide which revealed a statistically significant increase in area $\%$ of collagen, compared to the control as well as to the other subgroups (Table 12, Histogram 3).

Table (1): ANOVA one-way statistical analysis of the hepatotoxic effects of single toxic dose of thioridazine (Ib) and pimozide (Ic) compared with the control group (Ia) in rats

\begin{tabular}{|l|c|c|}
\hline Groups and parameters & Mean \pm SD & F \\
\hline AST (u/l) & & \\
Control (Ia) & $20.2 \pm 8.5$ & \\
Ib & $52.8 \pm 9.4^{\mathrm{a}}$ & 28.6 \\
Ic & $64.2 \pm 25.1^{\mathrm{a}}$ & \\
\hline ALT (u/l) & & \\
Control (Ia) & $15.2 \pm 2.86$ & \\
Ib & $39.9 \pm 5^{\mathrm{a}}$ & 39.68 \\
Ic & $50.4 \pm 12.7^{\mathrm{a}}$ & \\
\hline
\end{tabular}

Number $=6$ rats $/$ group, ${ }^{a}=$ significant difference versus the control group at $P \leq 0.05$.

Table (2): ANOVA one-way statistical analysis of the effects of single toxic dose of thioridazine (Ib) and pimozide (Ic) compared with the control group (Ia) on LDH activity and cholesterol in rats

\begin{tabular}{|l|c|c|}
\hline Groups and parameters & Mean \pm SD & F \\
\hline LDH (u/l) & & \\
Control (Ia) & $213.2 \pm 27.04$ & \\
Ib & $294 \pm 41.5^{\mathrm{a}}$ & 17.26 \\
Ic & $320 \pm 38.07^{\mathrm{a}}$ & \\
\hline Cholesterol (u/l) & & \\
Control (Ia) & $82.4 \pm 19.7$ & \\
Ib & $94.8 \pm 11.07$ & \\
Ic & $104 \pm 11.59$ & 3.123 \\
\hline
\end{tabular}

Number $=6$ rats/ group, ${ }^{a}=$ significant difference versus the control group (Ia) at $P \leq 0.05$.

Table (3): ANOVA one-way statistical analysis of the effects of single toxic dose of thioridazine (Ib) and pimozide (Ic) compared with the control group (Ia) on kidney function in rats

\begin{tabular}{|l|c|c|}
\hline Groups and parameters & Mean \pm SD & F \\
\hline Urea (mg/dl) & & \\
Control (Ia) & $14.4 \pm 3.5$ & \\
Ib & $19.4 \pm 3.6$ & 2.74 \\
Ic & $22.2 \pm 8.3$ & \\
\hline Creatinine (mg/dl) & & \\
Control (Ia) & $0.6 \pm 0.31$ & \\
Ib & $0.78 \pm 0.41$ & \\
Ic & $1.02 \pm 0.41$ & 1.24 \\
\hline
\end{tabular}




\begin{tabular}{|l|l|l|}
\hline Uric acid (mg/dl) & & \\
Control (Ia) & $2.1 \pm 4.1$ & \\
Ib & $2.2 \pm 4.3$ & \\
Ic & $2.3 \pm 4.2$ & 0.42 \\
\hline
\end{tabular}

Number $=6$ rats $/$ group, Significance was set at $P$ value $\leq 0.05$

Table (4): ANOVA one-way statistical analysis of the hepatotoxic effects of thioridazine (subgroups IIb and IIc) compared with the control group (IIa) in rats

\begin{tabular}{|l|c|c|}
\hline \multicolumn{1}{|c|}{ Groups and parameters } & Mean \pm SD & F \\
\hline AST (u/l) & $19.7 \pm 9.3$ & \\
Control IIa & $51.1 \pm 6.9^{\mathrm{ac}}$ & 43.1 \\
Subgroup IIb & $93.6 \pm 8.2^{\mathrm{ab}}$ & \\
Subgroup IIc & & \\
\hline ALT (u/l) & $15.4 \pm 2.6$ & \\
Control IIa & $38.9 \pm 5.1^{\mathrm{ac}}$ & 81.2 \\
Subgroup IIb & $69.1 \pm 5.3^{\mathrm{ab}}$ & \\
Subgroup IIc &
\end{tabular}

Number $=6$ rats/group

${ }^{a}=$ significant difference versus the control group (IIa) at $P \leq 0.05$.

${ }^{b}=$ significant difference versus group IIb at $P \leq 0.05$.

${ }^{c}=$ significant difference versus group IIc at $P \leq 0.05$.

$I I a=$ control group $I I b=$ Rats received doses equal to ${ }^{1} / 20$ of $L D_{50}$ of thioridazine for 12 weeks IIc $=$ Rats received doses equal to ${ }_{10}^{10}$ of $L D_{50}$ of thioridazine for 12 weeks.

Table (5): ANOVA one-way statistical analysis of the effects of thioridazine (subgroups IIb and IIc) compared with the control group (IIa) on LDH activity and cholesterol in rats

\begin{tabular}{|l|c|c|}
\hline Groups and parameters & Mean \pm SD & F \\
\hline LDH (u/l) & & \\
Control IIa & $212.7 \pm 25.6$ & \\
Subgroup IIb & $330.1 \pm 19.5^{\mathrm{a}}$ & 16.94 \\
Subgroup IIc & $393.3 \pm 37.4^{\mathrm{a}}$ & \\
\hline Cholesterol (u/l) & & \\
Control IIa & $81.7 \pm 20.2$ & \\
Subgroup IIb & $106.5 \pm 16.7$ & 29.4 \\
Subgroup IIc & $118.9 \pm 11.4$ & \\
\hline
\end{tabular}

Number $=6$ rats $/$ group

${ }^{a}=$ significant difference versus the control group (IIa) at $P \leq 0.05$.

$I I a=$ control group $I I b=$ Rats received doses equal to ${ }^{1} / 20$ of $L D_{50}$ of thioridazine for 12 weeks IIc $=$ Rats received doses equal to ${ }^{1} / 10$ of $L D_{50}$ of thioridazine for 12 weeks.

Table (6): ANOVA one-way statistical analysis of the effects of thioridazine (subgroups IIb and IIc) compared with the control group (IIa) on renal function in rats

\begin{tabular}{|l|c|c|}
\hline Groups and parameters & Mean \pm SD & F \\
\hline Urea (mg/dl) & & \\
Control IIa & $14.0 \pm 4.2$ & \\
Subgroup IIb & $19.8 \pm 3.9$ & 1.64 \\
Subgroup IIc & $27.6 \pm 4.8^{\mathrm{a}}$ & \\
\hline Creatinine (mg/dl) & & \\
Control IIa & $0.6 \pm 0.35$ & \\
Subgroup IIb & $0.68 \pm 0.39^{\mathrm{c}}$ & 1.86 \\
Subgroup IIc & $1.35 \pm 0.34^{\mathrm{ab}}$ & \\
\hline Uric acid (mg/dl) & & \\
Control IIa & $2.8 \pm 1.2$ & \\
Subgroup IIb & $2.9 \pm 0.8$ & 3.01 \\
Subgroup IIc & $4.2 \pm 0.7$ & \\
\hline
\end{tabular}

Number $=6$ rats/ group

${ }^{a}=$ significant difference versus the control group (IIa) at $P \leq 0.05$.

${ }^{b}=$ significant difference versus group IIb at $P \leq 0.05$. 
${ }^{c}=$ significant difference versus group IIc at $P \leq 0.05$.

$I I a=$ control group $I I b=$ Rats received doses equal to ${ }^{1} / 20$ of $L D_{50}$ of thioridazine for 12 weeks IIc $=$ Rats received doses equal to ${ }_{10}$ of $L D_{50}$ of thioridazine for 12 weeks.

Table (7): ANOVA one-way statistical analysis of the hepatotoxic effects of pimozide (subgroups IId and IIe) compared with the control group (IIa) in rats.

\begin{tabular}{|l|c|c|}
\hline Groups and parameters & Mean \pm SD & F \\
\hline AST (u/l) & $19.7 \pm 9.3$ & \\
Control IIa & $60.6 \pm 13.1^{\mathrm{ac}}$ & 36.3 \\
Subgroup IId & $103.2 \pm 11.5^{\mathrm{ab}}$ & \\
Subgroup IIe & & \\
\hline ALT (u/l) & $15.4 \pm 2.6$ & \\
Control IIa & $47.5 \pm 11.9^{\mathrm{ac}}$ & 28.5 \\
Subgroup IId & $89.1 \pm 9.3^{\mathrm{ab}}$ & \\
Subgroup IIe &
\end{tabular}

Number $=6$ rats $/$ group

${ }^{a}=$ significant difference versus the control group (IIa) at $P \leq 0.05$.

${ }^{b}=$ significant difference versus group IId at $P \leq 0.05$.

${ }^{c}=$ significant difference versus group IIe at $P \leq 0.05$.

$I I a=$ control group $I I d=$ Rats received doses equal to ${ }^{1} / 50$ of $L D_{50}$ of pimozide for 12 weeks IIe = Rats received doses equal to ${ }_{25}$ of $L D_{50}$ of pimozide for 12 weeks.

Table (8): ANOVA one-way statistical analysis of the effects of pimozide (subgroups IId and IIe) compared with the control group (IIa) on LDH activity and cholesterol in rats.

\begin{tabular}{|l|l|c|}
\hline Groups and parameters & \multicolumn{1}{|c|}{ Mean \pm SD } & F \\
\hline LDH (u/l) & $212.7 \pm 25.6$ & \\
Control IIa & $420.3 \pm 20.4^{\text {ac }}$ & 49.2 \\
Subgroup IId & $500.1 \pm 30.5^{\text {ab }}$ & \\
Subgroup IIe & & \\
\hline Cholesterol (u/l) & $81.7 \pm 20.2$ & \\
Control IIa & $181.3 \pm 18.5^{\text {ac }}$ & 29.8 \\
Subgroup IId & $242.0 \pm 24.6^{\text {ab }}$ & \\
Subgroup IIe & \\
\hline
\end{tabular}

Number $=6$ rats $/$ group

${ }^{a}=$ significant difference versus the control group (IIa) at $P \leq 0.05$.

${ }^{b}=$ significant difference versus group IId at $P \leq 0.05$.

${ }^{c}=$ significant difference versus group IIe at $P \leq 0.05$.

$I I a=$ control group $I I d=$ Rats received doses equal to ${ }^{1} / 5_{0}$ of $L D_{50}$ of pimozide for 12 weeks IIe $=$ Rats received doses equal to ${ }^{1}{ }_{25}$ of $L D_{50}$ of pimozide for 12 weeks.

Table (9): ANOVA one-way statistical analysis of the effects of pimozide (subgroups IId and IIe) compared with the control group (IIa) on renal function in rats

\begin{tabular}{|l|c|c|}
\hline Groups and parameters & Mean \pm SD & F \\
\hline Urea (mg/dl) & $14.0 \pm 4.2$ & \\
Control IIa & $18.2 \pm 5.6$ & 1.48 \\
Subgroup IId & $28.4 \pm 5.3^{\mathrm{a}}$ & \\
Subgroup IIe & & \\
\hline Creatinine (mg/dl) & $0.6 \pm 0.35$ & \\
Control IIa & $0.77 \pm 0.26$ & 0.39 \\
Subgroup IId & $1.65 \pm 0.41^{\mathrm{a}}$ & \\
Subgroup IIe & & \\
\hline Uric acid (mg/dl) & $2.8 \pm 1.2$ & \\
Control IIa & $3.2 \pm 0.91$ & 1.45 \\
Subgroup IId & $3.5 \pm 0.96$ & \\
Subgroup IIe &
\end{tabular}

Number $=6$ rats $/$ group 
${ }^{a}=$ significant difference versus the control group (IIa) at $P \leq 0.05$.

$I I a=$ control group IId = Rats received doses equal to $1 / 50$ of LD50 of pimozide for 12 weeks IIe $=$ Rats received doses equal to 1/25 of LD50 of pimozide for 12 weeks.

Table (10): Mean Sinusoidal Area $(\mu 2)( \pm$ SD) in liver sections of the studied groups.

\begin{tabular}{|c|c|c|c|c|c|c|c|}
\hline \multirow[b]{2}{*}{ Group } & \multirow[b]{2}{*}{$\begin{array}{l}\text { Control } \\
\text { Ia }\end{array}$} & \multicolumn{2}{|c|}{ Acute Toxicity } & \multicolumn{4}{|c|}{ Subchronic Toxicity } \\
\hline & & $\begin{array}{l}\text { Thioridazine } \\
\text { Ib }\end{array}$ & $\begin{array}{l}\text { Pimozide } \\
\text { Ic }\end{array}$ & $\begin{array}{l}\text { Thioridazine } \\
\text { IIb }\end{array}$ & $\begin{array}{c}\text { Thioridazine } \\
\text { IIc }\end{array}$ & $\begin{array}{l}\text { Pimozide } \\
\text { IId }\end{array}$ & $\begin{array}{r}\text { Pimozide } \\
\text { IIe }\end{array}$ \\
\hline $\begin{array}{l}\text { Mean } \\
\text { Sinusoidal } \\
\text { Area }\end{array}$ & $\begin{array}{c}116.7 \pm \\
18.5\end{array}$ & $\begin{array}{c}123.0 \pm \\
19.1\end{array}$ & $\begin{array}{c}129.7 \pm \\
19.3\end{array}$ & $\begin{array}{c}125.0 \pm \\
19.6\end{array}$ & $\begin{array}{c}287.9 \pm \\
29.6 * \bullet \#\end{array}$ & $\begin{array}{c}129.0 \pm \\
20.4\end{array}$ & $\begin{array}{l}251.0 \pm \\
25.3 * \bullet \#\end{array}$ \\
\hline $\begin{array}{l}P \text { value } \\
\text { significant at } \\
p<0.05\end{array}$ & & & & & $\begin{array}{c}0.001 \mathrm{vs} \mathrm{Ia}^{*}, \mathrm{Ib}^{\bullet} \\
\text { and IIb\# }\end{array}$ & & $\begin{array}{l}0.001 \mathrm{vs} \mathrm{Ia}^{*}, \\
\text { Ic• and IId\# }\end{array}$ \\
\hline
\end{tabular}

$*=$ significantly different from Ia. $\cdot$ on IIc column $=$ significantly different from Ib. \# on IIc column $=$ significantly different from IIb. • on IIe column = significantly different from Ic. \# on IIe column = significantly different from IId .

Table (11): Mean Glomerular Area $(\mu 2)( \pm$ SD) in kidney sections of the studied groups

\begin{tabular}{|c|c|c|c|c|c|c|c|}
\hline \multirow[b]{2}{*}{ Group } & \multirow[b]{2}{*}{$\begin{array}{c}\text { Control } \\
\text { Ia }\end{array}$} & \multicolumn{2}{|c|}{ Acute Toxicity } & \multicolumn{4}{|c|}{ Subchronic Toxicity } \\
\hline & & $\begin{array}{c}\text { Thioridazine } \\
\text { Ib }\end{array}$ & $\begin{array}{l}\text { Pimozide } \\
\text { Ic }\end{array}$ & $\begin{array}{l}\text { Thioridazine } \\
\text { IIb }\end{array}$ & $\begin{array}{l}\text { Thioridazine } \\
\text { IIc }\end{array}$ & $\begin{array}{c}\text { Pimozide } \\
\text { IId }\end{array}$ & $\begin{array}{c}\text { Pimozide } \\
\text { IIe }\end{array}$ \\
\hline $\begin{array}{c}\text { Mean } \\
\text { Glomerular } \\
\text { Area }\end{array}$ & $\begin{array}{c}8957.3 \\
\pm \\
2389.4\end{array}$ & $\begin{array}{c}6828.6 \pm \\
1951.7\end{array}$ & $\begin{array}{c}6714.7 \pm \\
1890.3\end{array}$ & $\begin{array}{r}6123.2 \pm \\
1662.4\end{array}$ & $\begin{array}{c}4112.3 \pm \\
1637.0^{*} \bullet \#\end{array}$ & $\begin{array}{c}6002.2 \pm \\
1621.1\end{array}$ & $\begin{array}{c}4923.8 \pm \\
1536.7^{*} \cdot \#\end{array}$ \\
\hline $\begin{array}{c}P \text { value } \\
\text { significant } \\
\text { at } p<0.05\end{array}$ & & & & & $\begin{array}{c}0.001 \mathrm{vs} \mathrm{Ia*} \\
0.367 \mathrm{vs} \mathrm{Ib} \bullet \\
\text { andIIb\# }\end{array}$ & & $\begin{array}{c}0.001 \mathrm{vs} \mathrm{Ia}^{*}, \\
0.367 \mathrm{vs} \mathrm{Ic} \bullet \text { and } \\
\text { IId\# }\end{array}$ \\
\hline
\end{tabular}

*= significantly different from Ia $\cdot$ on IIc column = significantly different from Ib. \# on IIc column = significantly different from IIb. • on IIe column = significantly different from Ic. \# On IIe column = significantly different from IId.

Table (12): Mean area \% of collagen fiber content $( \pm \mathrm{SD})$ in Masson's-Trichrome stained ventricular sections of the studied groups

\begin{tabular}{|c|c|c|c|c|c|c|c|}
\hline \multirow[t]{2}{*}{ Group } & \multirow{2}{*}{$\begin{array}{c}\text { Control } \\
\text { Ia }\end{array}$} & \multicolumn{2}{|c|}{ Acute Toxicity } & \multicolumn{4}{|c|}{ Subchronic Toxicity } \\
\hline & & $\begin{array}{c}\text { Thioridazine } \\
\text { Ib }\end{array}$ & $\begin{array}{l}\text { Pimozide } \\
\text { Ic }\end{array}$ & $\begin{array}{c}\text { Thioridazine } \\
\text { IIb }\end{array}$ & $\begin{array}{c}\text { Thioridazine } \\
\text { IIc }\end{array}$ & $\begin{array}{l}\text { Pimozide } \\
\text { IId }\end{array}$ & $\begin{array}{l}\text { Pimozide } \\
\text { IIe }\end{array}$ \\
\hline $\begin{array}{l}\text { Mean area } \\
\% \text { of } \\
\text { collagen } \\
\text { fibers }\end{array}$ & $2.9 \pm 0.12$ & $3.2 \pm 0.21$ & $3.5 \pm 0.24$ & $3.7 \pm 0.5$ & $3.7 \pm 0.5$ & $3.9 \pm 0.6$ & $7.4 \pm 0.8^{*}$ \\
\hline $\begin{array}{c}\text { P value } \\
\text { significant } \\
\text { at } p<0.05\end{array}$ & & & & & & & $\begin{array}{l}0.001 * \text { vs. } \\
\text { All } \\
\text { subgroups }\end{array}$ \\
\hline
\end{tabular}

* = Significantly different from ALL other subgroups at $P \leq 0.05$.

\section{Plate 1: Photomicrographs of liver sections}

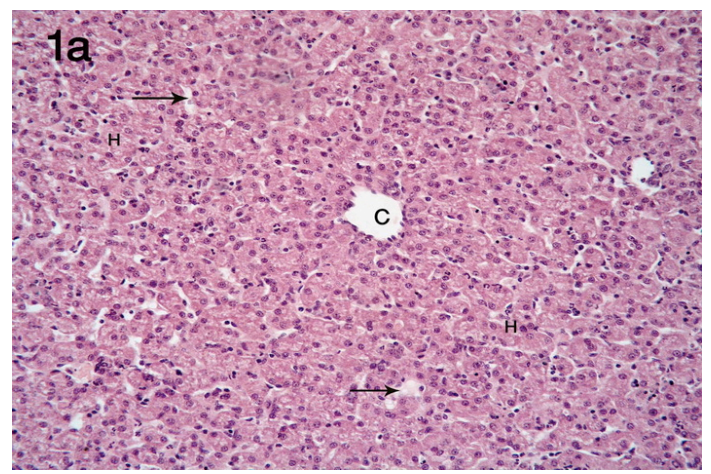

Figure 1a: Control group showing central vein $(C)$ in

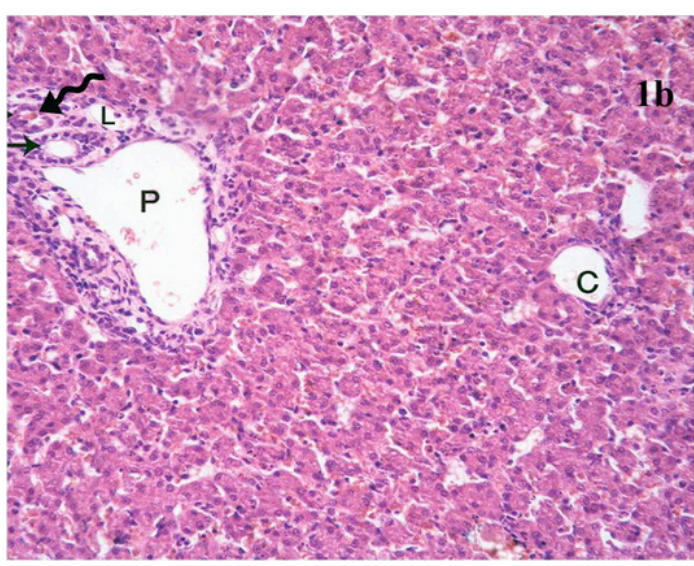

Figure 1b: Control group showing central vein $(C)$ in 
the center of a hepatic lobule. Hepatocytes (H) have central rounded nuclei and acidophilic cytoplasm. They are arranged in the form of hepatic plates, separated by blood sinusoids (arrows) (H\&E X200).

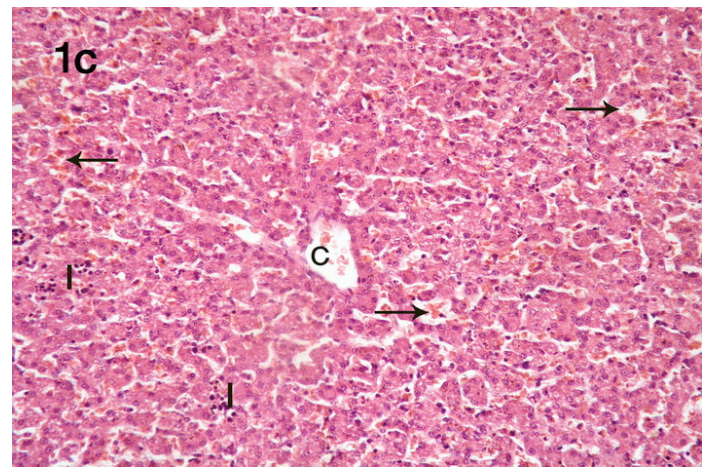

Figure 1c: A liver section from a rat receiving single oral toxic dose of pimozide (Ic) showing congestion of central vein $(C)$ in the center of a hepatic lobule, congestion of blood sinusoids separating hepatic plates (arrows). Mononuclear cellular infiltration (I) is noted in the portal tracts $(\mathrm{H} \& \mathrm{E} \mathbf{X 2 0 0})$.

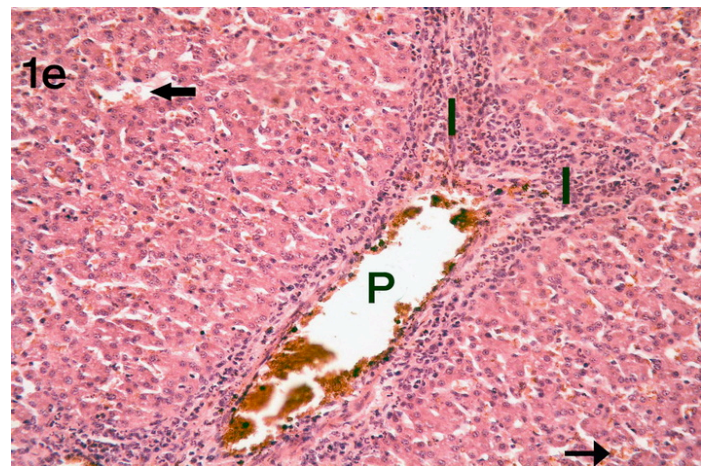

Figure 1e: A liver section from subgroup IId showing dilatation of blood sinusoids (arrows) and congestion of portal vein ( $P$ ). Severe mononuclear cellular infiltration $(I)$ is demonstrated inside the portal tracts (H\&E X200).

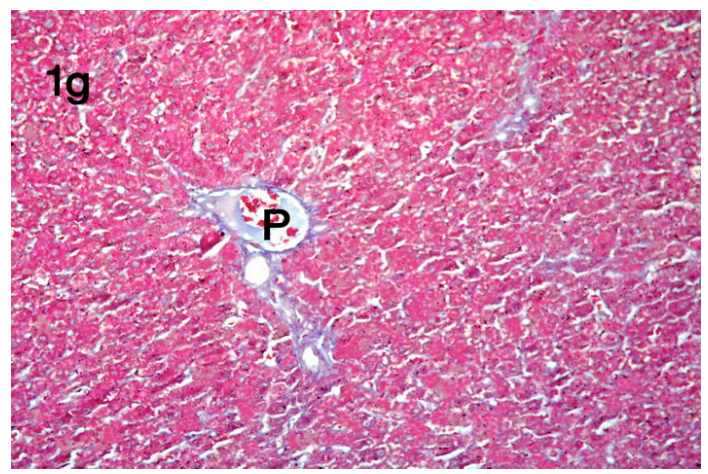

Figure 1g: Control group showing the presence of few collagen fibers deposited around the portal vein $(P)$ in the center of a hepatic lobule. A portal tract is observed containing a branch of the portal vein $(P)$, branch of the hepatic artery (wavy arrow), bile duct with cuboidal lining cells (arrow) and lymph vessel $(L)$ (H\&E X200).

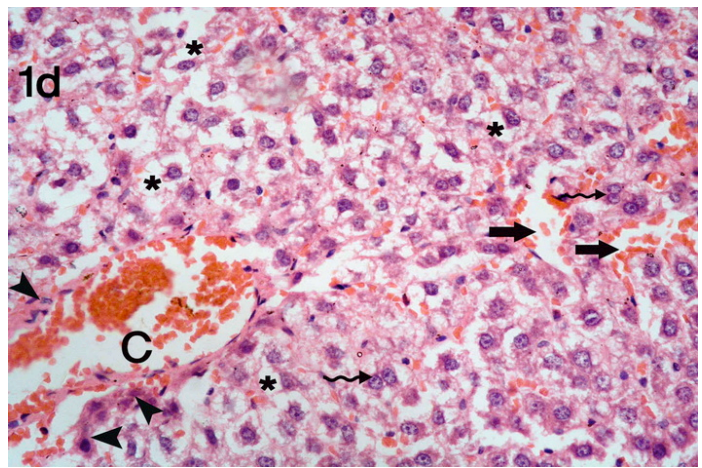

Figure 1d: A liver section from subgroup IIc showing marked congestion of central vein (C) and blood sinusoids (arrows) associated with vacuolar degenerative changes of hepatocytes (*). Some cells are binucleated (wavy arrows) (H\&E X400).

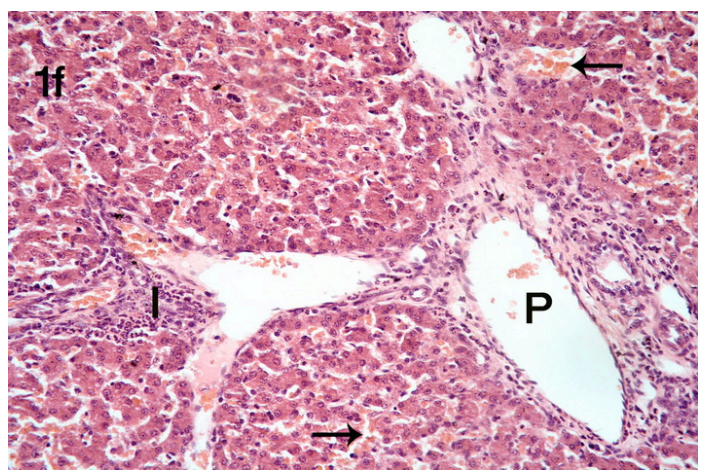

Figure 1f: A liver section from subgroup IIe showing congestion of blood sinusoids (arrows) and dilatation of the portal vein (P). Mononuclear cellular infiltration is observed (I) (H\&E X200).

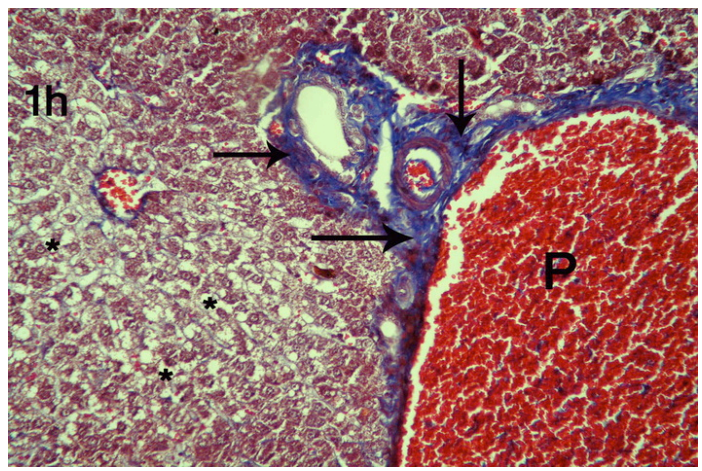

Figure 1h: A liver section from subgroup IIe showing marked deposition of collagen fibers (arrow) around 
the portal tract and around the walls of blood sinusoids (Masson's Trichrome X200). the portal tract. Portal vein is congested $(P)$. Vacuolar degenerative cytoplasmic changes are evident in the hepatocytes (*) near to the fibrotic area (Masson's Trichrome X200).

\section{Plate 2: Photomicrographs of kidney sections}

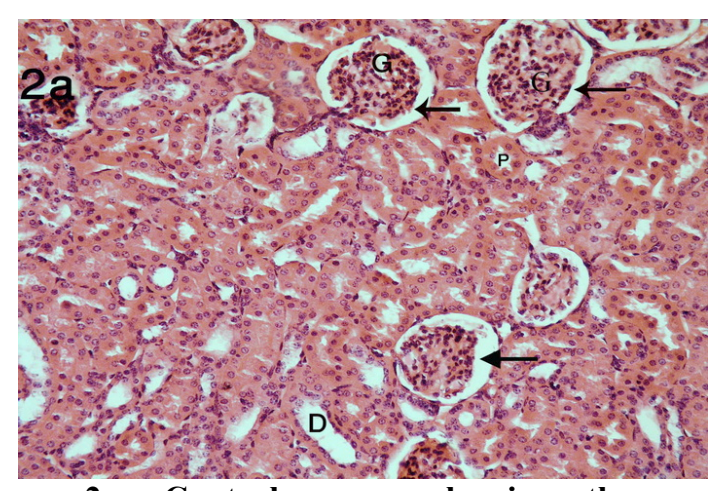

Figure 2a: Control group showing the normal histological structure of glomerular capillary tufts (G) surrounded by Bowman's capsule enclosing Bowman's space (arrows). Cortical tissue contains proximal (P) and distal convoluted tubules (D) (H\&E X200).

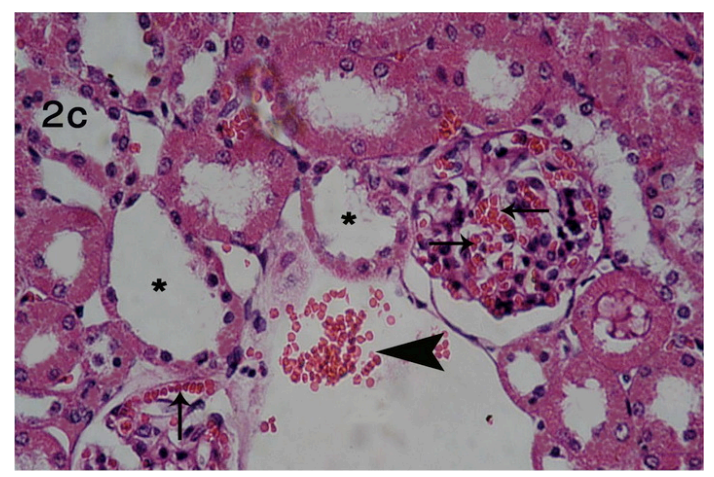

Figure 2c: A kidney section from a rat receiving single oral toxic dose of pimozide (Ic) showing congested glomerular capillaries (arrows) as well as extravasation of RBCs in the renal interstitium (arrowhead). Two distal tubules exhibit widened lumina (*) (H\&E X400).

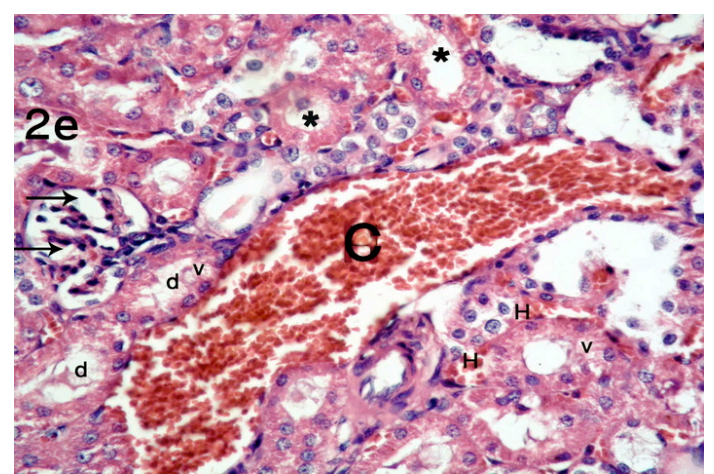

Figure 2e: A kidney section from subgroup IIc showing distorted renal corpuscle with separated glomeruli (arrows). Cells lining renal tubules show

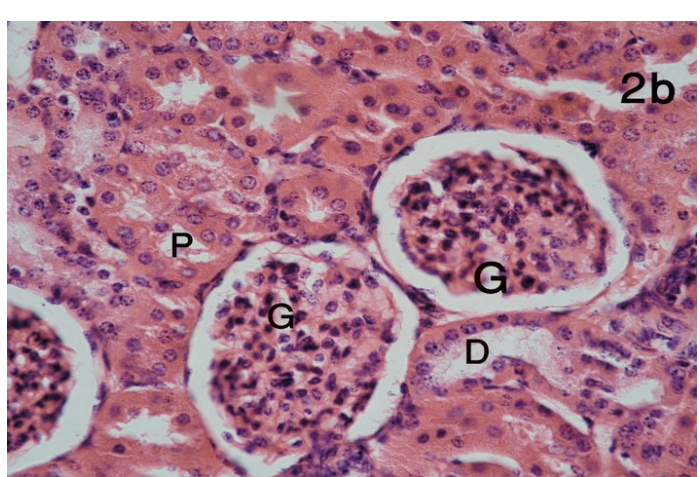

Figure 2b: Control group showing normal appearance of Malpighian corpuscles with glomeruli (G). Proximal convoluted tubules $(P)$ have narrow lumen and are lined with pyramidal cells having deeply acidophilic cytoplasm and well formed apical brush border. Distal tubules (D) have wider lumen and are lined with cuboidal cells having less acidophilic cytoplasm (H\&E X400).

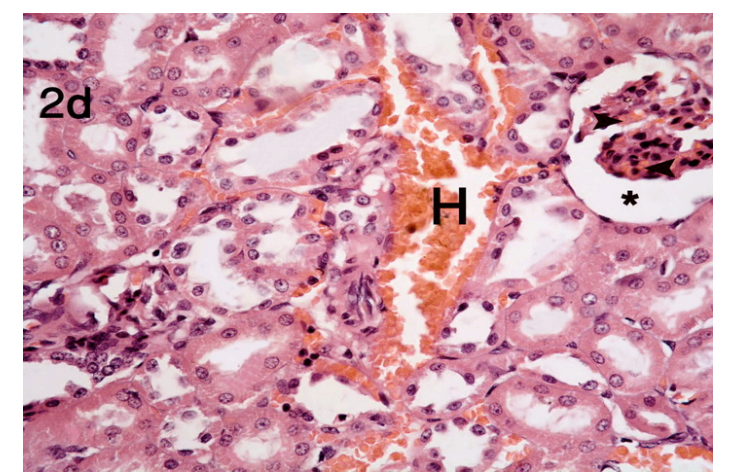

Figure 2d: A kidney section from subgroup IIb showing distortion of glomerular capillaries with widening of Bowman's space (*). Congestion of glomerular capillaries is noted (arrowheads) together with hemorrhage and extravasation of $\mathrm{RBCs}(\mathrm{H})$ in the renal interstitium (H\&E X200).

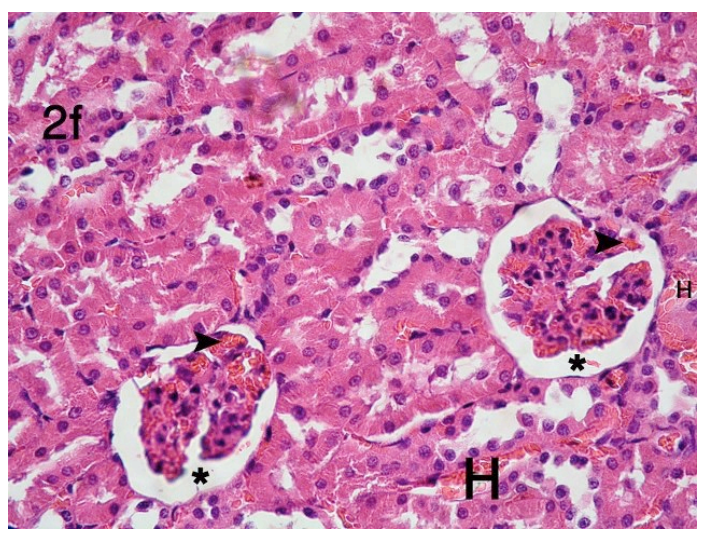

Figure 2f: A kidney section from subgroup IId showing disrupted glomerular capillaries with widened Bowmans space (*). Congestion of glomerular 
cytoplasmic vacuolation (v) and shedding of cells in lumina (*). Cellular debris (d) are dislodged in other tubules. Severe congestion $(C)$ of blood vessel and hemorrhage (H) are noted (H\&E X400). capillaries (arrowheads) is noted as well as interstitial hemorrhage (H) (H\&E X400).

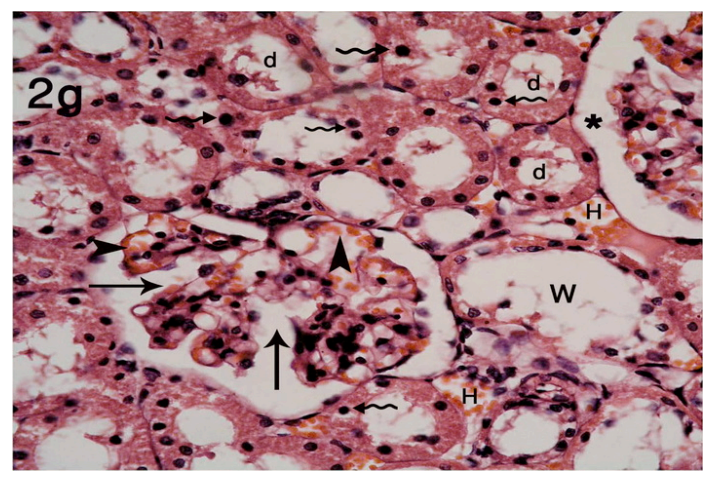

Figure 2g: A kidney section from subgroup IIe showing distorted outline of a renal corpuscle showing splitting (arrows) and congestion (arrowheads) of glomerular capillaries with widening of Bowmans space (*). Some tubules have widened lumina $(W)$. Several pyknotic nuclei (wavy arrows) are seen lining the tubules. Cellular debris is observed in the tubular lumina (d). Most of the proximal tubules have distorted brush border. Interstitial hemorrhage is observed $(\mathrm{H})(\mathrm{H} \& \mathrm{E} \mathrm{X} 400)$.

\section{Plate 3: Photomicrographs of cardiac muscle sections}

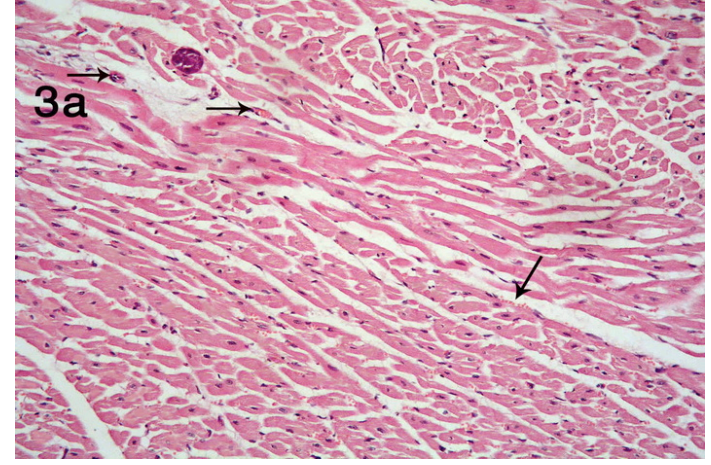

Figure 3a: Control group showing normal histological architecture of cardiac myocytes arranged in different directions. Myocytes exhibit acidophilic sarcoplasm and central oval pale nuclei. Note the presence of blood vessels (arrows) in between the myocytes (H\&E X200).

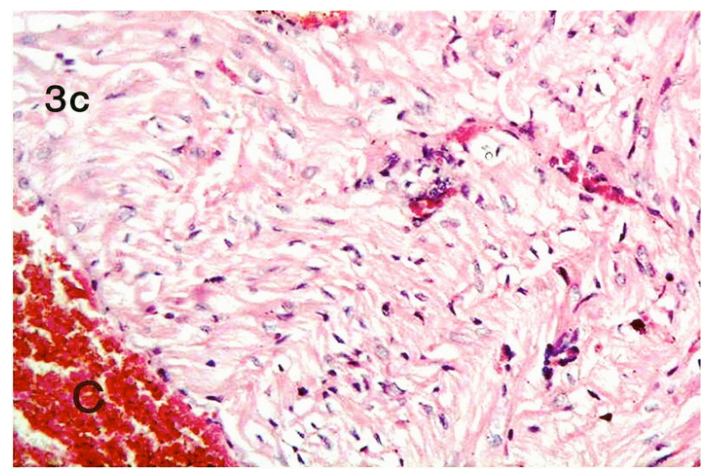

Figure 3c: Cardiac muscle section from a rat receiving single oral toxic dose of pimozide showing marked dilatation and congestion of a blood vessel (C). Cardiac myocytes appear disorganized with vacuolated cytoplasm (H\&E X200).

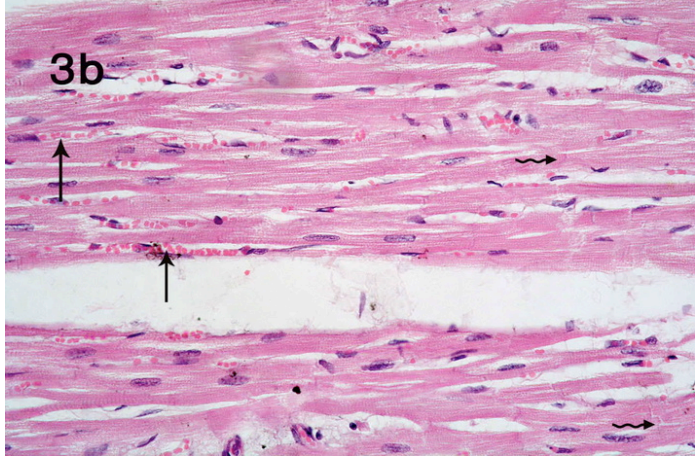

Figure 3b: Control group showing clear striations of sarcoplasm and intercalated discs joining adjacent myocytes (wavy arrows). Blood vessels (arrows) are located in between the myocytes (H\&E X400).

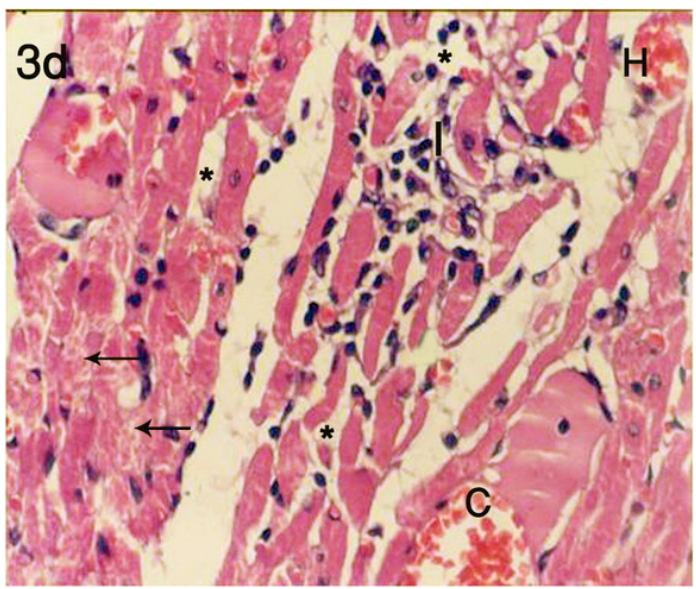

Figure 3d: Cardiac muscle section from subgroup IIc showing disruption of cardiac myocytes which appear markedly separated (*). Hemorrhage (H) was noted between the disrupted myocytes as well as accumulation of homogenous acidophilic exudates between the muscle fibers $(E)(H \& E$ X400). 


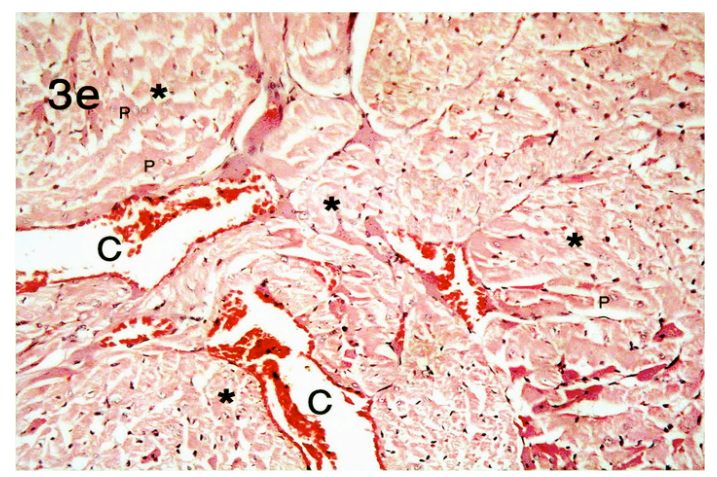

Figure 3e: Cardiac muscle section from subgroup IId showing that the majority of fibers exhibit cytoplasmic degeneration with separated myofibrils (*). Some cardiac myocytes exhibit deeply acidophilic sarcoplasm and peripheral nuclei $(P)$. Blood capillaries appear markedly congested (C) (H\&E X 200).

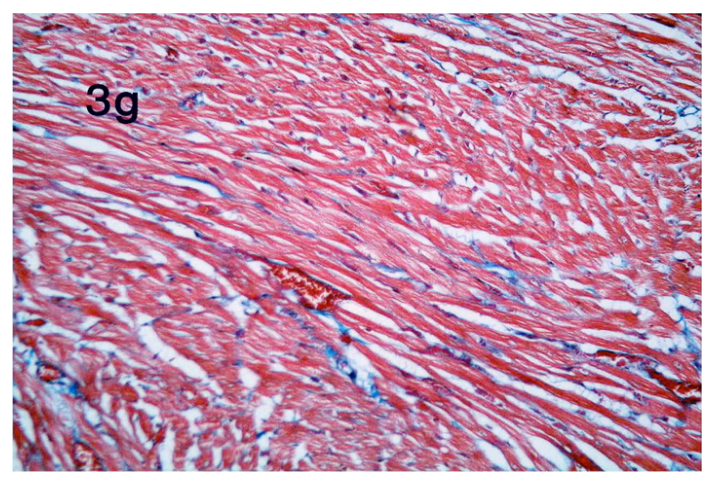

Figure 3g: Control group showing few collagen fibers (stained blue) in the connective tissue endomysium between cardiac muscle fibers (stained red) (Masson's Trichrome X 200).

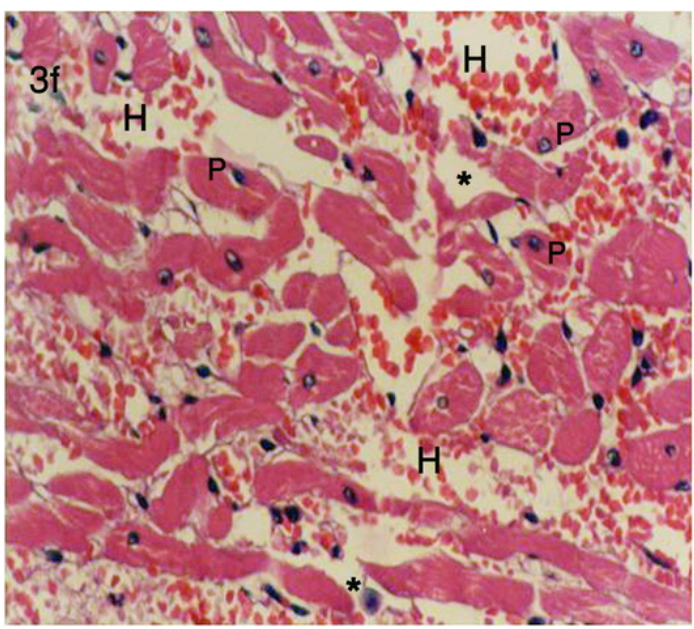

Figure 3f: Cardiac muscle section from subgroup IIe showing disruption of cardiac myocytes. Congestion of blood capillaries $(\mathrm{C})$ is noted between the myocytes as well as hemorrhage $(\mathrm{H})$ and extravasation of $\mathrm{RBCs}$ between the muscle fibers and accumulation of homogenous acidophilic exudates between the muscle fibers (E) (H\&E X 200).

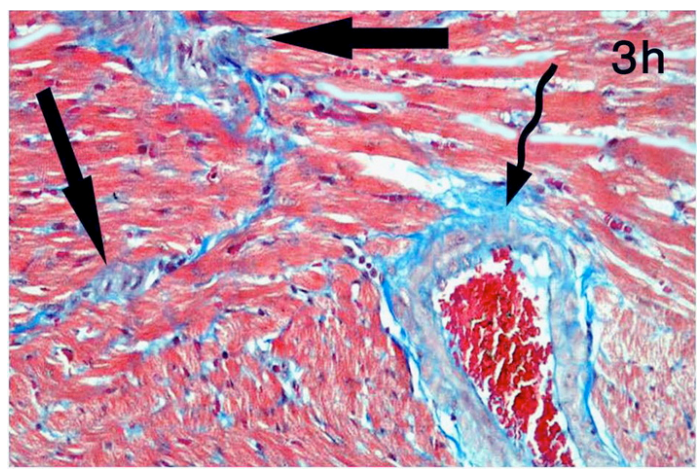

Figure 3h: Cardiac muscle section from subgroup IIe showing increased collagen fiber content between cardiac muscle fibers and bundles (arrows) as well as around the wall of a blood vessel (wavy arrow) (Masson's Trichrome X 200).

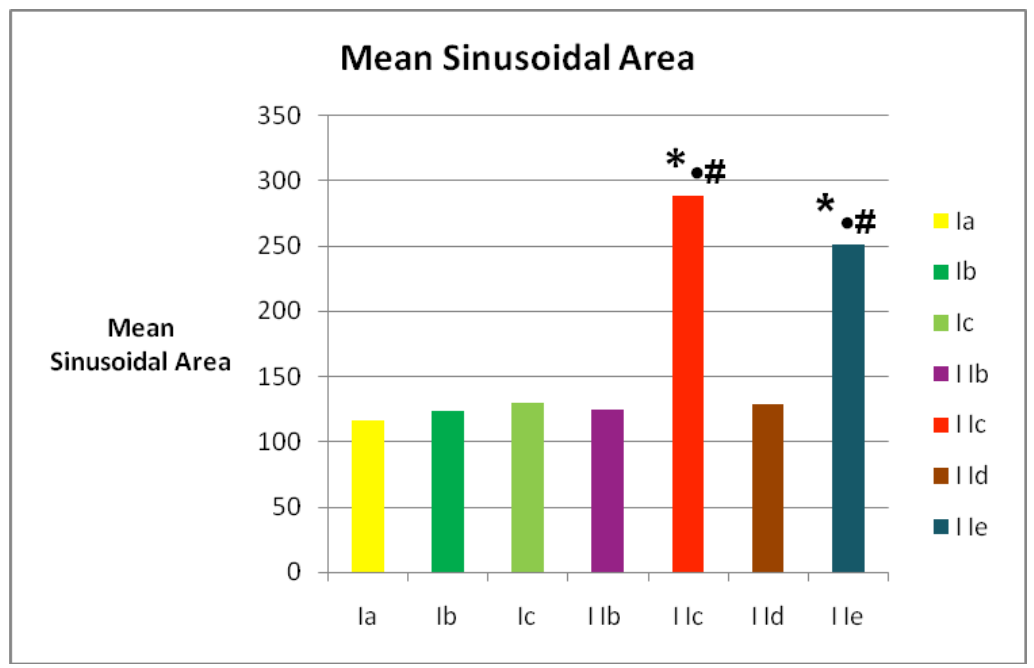


Histogram (1): Mean Sinusoidal Area $(\mu 2)$ in liver sections of the studied groups: control (Ia), acute thioridazine (Ib), acute pimozide (Ic), subchronic thioridazine (IIbandIIc), subchronic pimozide (IIdandIIe) (Number=6 rats/group).

$*=$ significantly different from Ia. $\cdot$ on IIc column = significantly different from Ib. \# on IIc column $=$ significantly different from IIb. • on IIe column = significantly different from Ic. \# On IIe column = significantly different from IId.

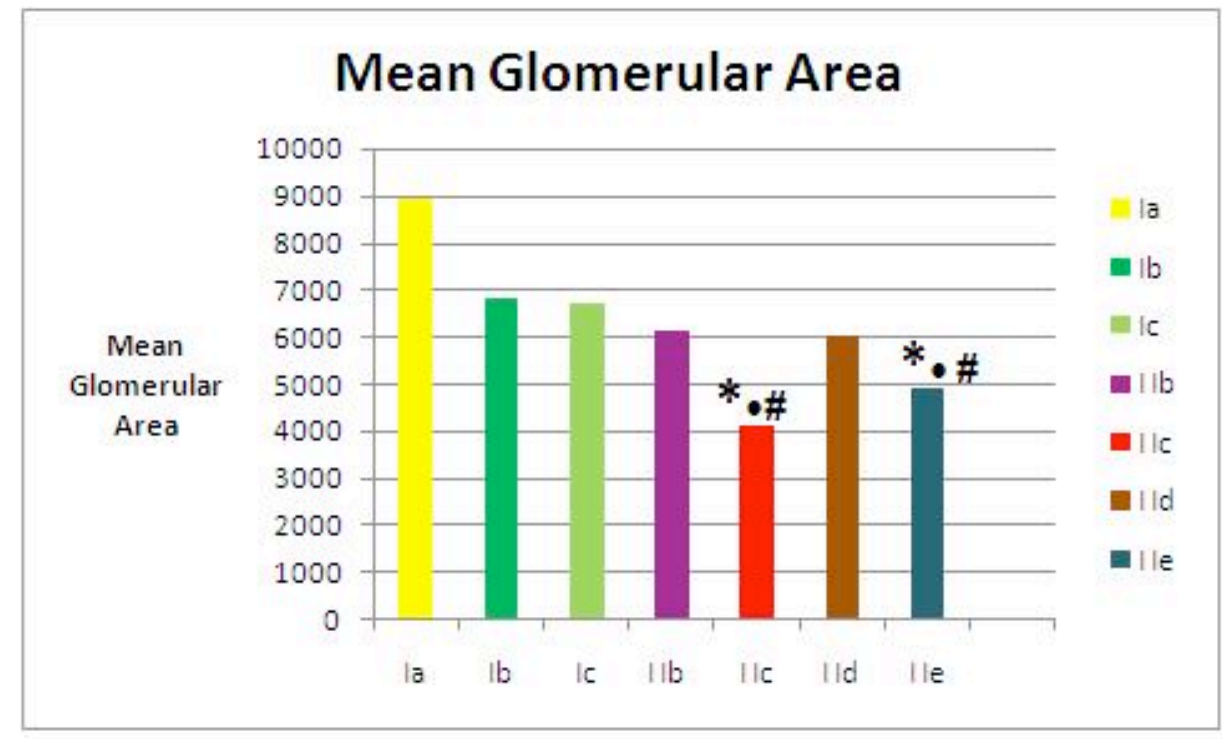

Histogram (2): Mean Glomerular Area $(\mu 2)$ in kidney sections of the studied groups: control (Ia), acute thioridazine (Ib), acute pimozide (Ic), subchronic thioridazine (IIbandIIc), subchronic pimozide (IIdandIIe) (Number $=6$ rats/group).

*= significantly different from Ia. • on IIc column = significantly different from Ib. \# on IIc column = significantly different from IIb. • on IIe column = significantly different from Ic. \# on IIe column = significantly different from IId.

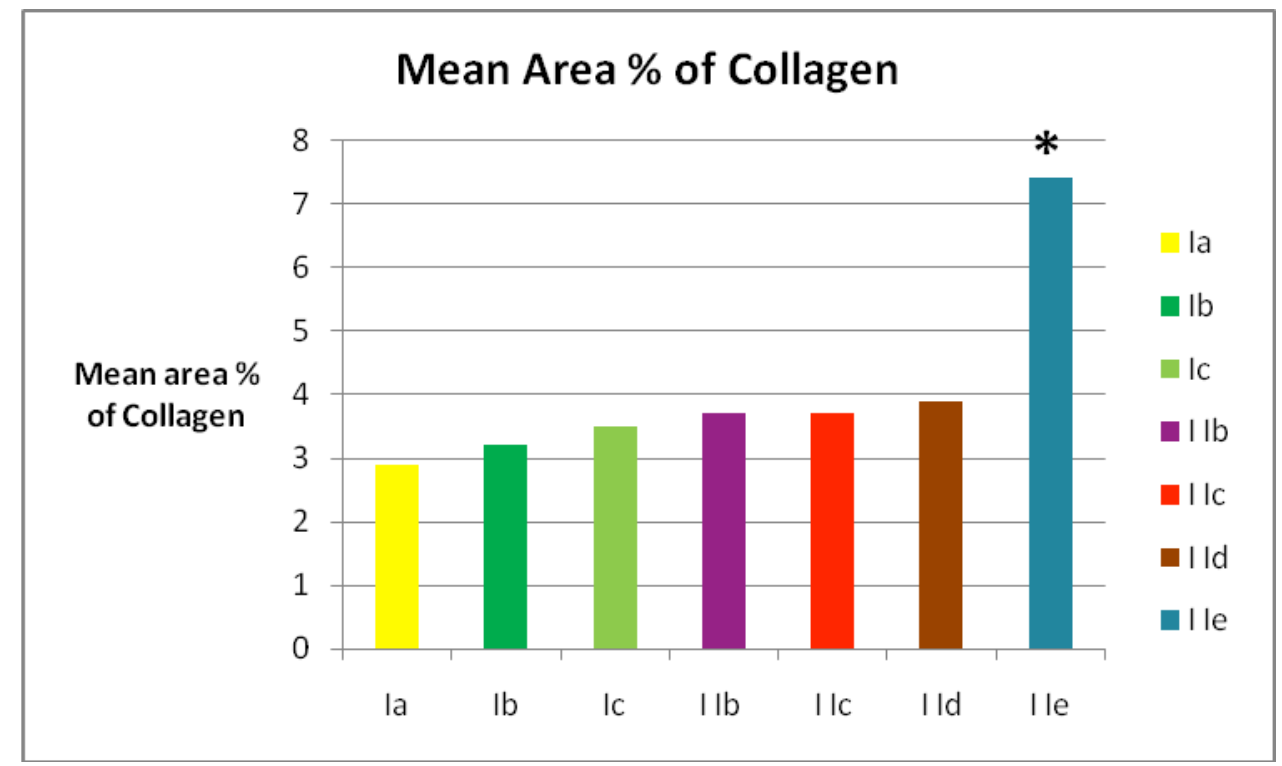

Histogram 3: Mean area \% of collagen fiber content in Masson's-Trichrome stained ventricular sections of the studied groups: control (Ia), acute thioridazine (Ib), acute pimozide (Ic), subchronic thioridazine (IIbandIIc), subchronic pimozide (IIdandIIe) (Number=6 rats/group).

* =Significantly different from ALL other subgroups at $P \leq 0.05$.

\section{Discussion}

Antipsychotic drugs are a potent group of drugs that therapeutically modify behavior (Schonwald, 2001). Toxicity of antipsychotic drugs occurs mainly in patients treated with first generation antipsychotic agents. Thioridazine and pimozide are typical antipsychotic drugs belonging to phenothiazines and diphenylbutylpiperidines drug groups respectively and are commonly used to treat schizophrenia and other psychotic problems (Lieberman and Tasman, 2006).

In the present work, the single oral toxic dose of both studied drugs (thioridazine and pimozide) resulted in significant elevation of aspartate transaminase (AST) and alanine transaminase (ALT) which are biomarkers of liver injury, when compared 
to the control, where the elevation was more marked with acute pimozide therapy. These results could be explained by excessive degradation of the drugs by hepatocytes that may disrupt its cytoskeleton integrity and vascularity as reported by Arrese et al., (1998) and Moore (1999). At the morphological level, no abnormalities were reported with single toxic dose of thioridazine in spite of significant increase in the liver enzymes; this might be because it was an acute study with no sufficient time for the drug to cause insult.

$$
\text { Morphological abnormalities were }
$$
encountered only with the single toxic dose of pimozide where the liver sections of pimozide-treated rats showed congested central veins and hepatic blood sinusoids. Obstruction of portal vein blood flow to the liver can lead to dilatation of hepatic blood sinusoids because of excess sinusoidal volume (Kakar et al.,2004).

In a similar pattern, the single toxic dose of both studied drugs caused significant increase in LDH levels as compared with control rats. Cholesterol levels were elevated but did not express a significant increase compared to the control. Change in cholesterol levels was consistent with Jonathan and Carol (2004) who reported that antipsychotics including thioridazine are associated with higher risk of hyperlipidemia. They attributed that lipid deregulations to weight gain, dietary changes and the development of glucose intolerance. Moreover, Kristiana et al., (2010) referred that to the ability of the antipsychotic drugs to induce lipogenic genes which are believed to increase activation of the lipogenic transcription factors causing cholesterol to accumulate in the cells, preventing it from being esterified in the endoplasmic reticulum.

LDH changes could be attributed to the occurrence of histopathological changes in heart of rats received single toxic dose of pimozide that was in accordance with Haddad et al., (1998) and Yoram et al. (2005).

On the other hand, there were no detected morphological abnormalities in ventricular sections of the rats received single toxic dose of thioridazine but LDH was significantly elevated, as was previously reported by other investigators (Abernathy and Flockhart, 2000) which may be attributed to the functional disturbances that preceded the morphological changes which did not occur because there was no enough time after the intake of the single oral dose of thioridazine to induce them. This could be supported by the report of a case of life-threatening ventricular dysrhythmia where the ECG (electrocardiogram) showed delayed repolarization encountered with high toxic thioridazine plasma concentration (Sinkiewicz et al., 2006).

Histological abnormalities were detected after acute pimozide in the form of dilatation and congestion of blood vessels, disorganization and cytoplasmic vacuolation of cardiomyocytes. Similar results were observed by Yoram et al., (2005) who detected multiple large dilated blood vessels in myocardial sections of rats that received single toxic dose of pimozide.
Toxic insult of the drug on cardiomyocytes might result in loss of myofialments and consequently myofibrillar and cytoplasmic lysis, resulting in cardiac contractile dysfunction. It has been reported that cardiac dysfunction can result in impairment of liver functions due to venous congestion; a condition known as "congestive hepatopathy" (Giallourakis et al., 2002). Heart failure causes passive venous congestion of the liver by creating back-pressure in the systemic venous system, which is transmitted down the hepatic vein to the central veins (Naschitz et al., 2000). This could also explain sinusoidal as well as central vein dilatation reported in this study. Sinusoidal dilatation and congestion in liver is due to venous outflow impairment. This was in agreement with Kakar et al., (2004) who reported that hepatic sinusoidal congestion was associated with venous outflow impairment in two thirds of the examined liver biopsies from patients with sinusoidal dilatation.

Although no significant changes in kidney function tests of rats receiving single toxic dose of both drugs was encountered in the present study, kidney sections of rats which received acute pimozide showed markedly dilated and congested cortical vessels and glomerular capillaries. This might be explained by damage of endothelial cells of glomerular and cortical capillaries occurring as a non-specific reaction to the injurious effect of the drug (Ramot and Nyska 2007). This might be attributed to excessive renal activity since the main route of pimozide excretion is through the kidney. Noticeably, morphological abnormalities targeted the renal blood capillaries sparing the tubular architecture which might explain preservation of kidney function tests within the normal range.

Concerning subchronic toxicity study, there were significant elevations of AST and ALT levels after daily use of both drugs at the low as well as the high doses (subgroups IIb, IIc, IId, IIe) compared to the control $(\mathrm{P}<0.05)$ with more marked elevation achieved with the high doses and also with pimozide therapy. This was in accordance with Klaassen, (2001). who reported that drugs could impair bile acid uptake and canalicular contractility by acting on the sinusoidal membrane, inducing a decrease in the $\mathrm{Na}^{+}-\mathrm{K}^{+}$-ATPase necessary for $\mathrm{Na}$-dependent transport of bile salts across the plasma membrane. This would eventually result in accumulation of excess drug in pericanalicular spaces causing elevation of all liver enzymes.

On examination of the morphological changes, no alterations were encountered with low thioridazine dose in subgroup IIb, in spite of significantly elevated liver enzymes, this means that the liver doesn't respond morphologically at this drug concentration and needs larger dose to induce structural changes. On the other hand, it was found that in sections of subgroup IIc [higher thioridazine dose] congestion of central veins and hepatic blood sinusoids were noted, together with vacuolar degenerative changes in hepatocytes. Degenerative changes could be explained by exhaustion of liver cells in the metabolic process of drug degradation, causing disruption of cellular cytoskeletal integrity (Moore, 1999). 
Furthermore, stasis of blood in the sinusoids causes hepatocytes to become deoxygenated as a result of interruption of vascularity, resulting in atrophy and subsequently necrosis of hepatocytes, with elevation of serum transaminases levels (Geerts, 2001).

After pimozide therapy at both low and high doses, in addition to sinusoidal dilatation, congestion of portal vein was also noted. Pressure in the portal system depends on blood flow in the portal vein and the total hepatic resistance to outflow. Portal vein congestion reported in the study might result from periportal fibrosis, obstructing blood flow towards the portal vein (Toubia and Sanyal, 2008). This would create a back pressure, causing portal hypertension and congestion. Periportal fibrosis was proved in the current study in Masson's-trichrome stained sections of subgroup IIe detecting increased collagen fibers content around the portal tract. Sinusoidal dilatation and congestion can also occur in the setting of an inflammatory reaction or a result of a hypersensitivity reaction as previously noted (Geerts, 2001).

Evidence of sinusoidal dilatation was confirmed in the current study where morphometric measurements revealed a statistically significant increase in the sinusoidal area in liver sections of rats receiving high doses of both drugs (subgroups IIc and IIe) compared to the control as well as low doses subgroups.

Lower subchronic thioridazine dose (subgroup IIb) presented a significantly increased LDH level compared to the control value. However, on examining cardiac muscle sections, no abnormalities were detected. On the other hand, the rats receiving the higher thioridazine dose (subgroup IIc) showed significant LDH level elevation that was accompanied by disruption of cardiomyocytes, congestion and hemorrhage between the muscle fibers. No significant changes for cholesterol levels were encountered with either dose of thioridazine. Worth noting is that, both low and high doses of subchronic pimozide therapy resulted in significant elevation of LDH and cholesterol levels, certainly representing an alarm for increase the potential risk of cardiac problems with pimozide therapy (Drolet et al., 2001). This may be attributed to interaction of pimozide with multiple 12 neurotransmitter receptors involved in lipid metabolism regulation as previously reported (Baptisa et al., 2005).

Elevation of biochemical markers was parallel to the histomorphological abnormalities detected on examination. Most of cardiomyocytes exhibited cytoplasmic lysis, separation of myofibrils and loss of striations, while some fibers had deeply acidophilic cytoplasm and peripherally situated nuclei. Loss and separation of cardiomyocytes was further proved by detection of a statistically significant increase in the mean area $\%$ of collagen fiber content in subgroup IIe compared to the control as well as to the other subgroups, when measured by histomorphomertic analysis.

Congestion and hemorrhage detected in this study denotes a sign of cardiac ischemia. Ischemic effects might be due to increased diastolic duration and release of metabolic vasodilators as a part of multicomponent mechanism of the drug toxicity. This would be followed by subsequent intracellular acidosis, inhibition of oxidative phosphorylation and ATP depletion, further aggravating the myocardial abnormalities (Yoram et al., 2005). Additionally, generation of oxygen radicals and uncoupling of mitochondrial oxidative phosphorylation have been proposed to account for the reperfusion and dilatation of collaterals with the resultant ischemia (Klaassen, 2001).

Regarding kidney function tests, significant elevations of serum urea and creatinine were detected after treating rats with the higher doses of either drug and not with the lower treatment doses, as compared to the control values. No changes in serum uric acid were detected for either treatment dose for any of the drugs. This could be explained by the fact that kidney damage occurs to a significant extent before function becomes altered. Signs and symptoms of uremia start vaguely and become detectable when the function of at least two thirds of the nephrons is lost. Until then, kidney disease runs apparently silent. This is due to the ability of the remaining nephrons to undergo hypertrophy and functionally compensate for those that are lost (Snively and Gutierrez, 2004).

Secondary to the inability of the kidneys to properly get rid of waste products from the blood, toxic substances usually eliminated in urine accumulate in the blood and cause progressively deteriorated function of most other tissues and organs, seriously affecting the quality of life and may cause death (Goicoechea et al., 2010).

Serological analysis of kidney functions test matched the morphological renal abnormalities, where only mild alterations were perceived with the low doses of both drugs; mainly in the form of glomerular and peritubular capillary congestion in addition to distortion of glomerular capillary tufts. No tubular changes were detected and tubules appeared apparently normal. On the other hand, vascular, glomerular as well as tubular abnormalities were encountered with the high doses. These findings go hand in hand with Tutor-Crespo et al., (2007) who recorded several patterns of renal affection, both structurally and functionally induced by anti-psychotic drugs.

The marked disruption of tubular brush border was also encountered in the present study is probably associated with renal tubular injury. This was in agreement with Herak Kramberger and Sabolic, (2001) who concluded that the nephrotoxic drugs directly damage the integrity of proximal tubule cell plasma membrane, which might cause shortening and loss of microvilli. Thus the reduced reabsorpitive surface due to damaged integrity of brush border membrane might contribute to the reabsorpitive and secretory defects in these toxic states.

Tubular affection could be explained by the chemical toxicity of the drugs that induce apoptosis or even necrosis of tubular epithelial cells due to its accumulation in the tubules. As a consequence of the damage of the tubular structures by the triggering insult, an initial response to restore function starts, 
which eventually ends into pathological tissue destruction. During the restorative effort, an inflammatory response is initiated and tubular cells proliferate to compensate the dead cells. Eventually, the restorative process, for unknown reasons, causes an irreversible destructive effect inducing more tissue damage and destruction by apoptosis of tubular cells (Nony and Schnellmann, 2001).

López-Novoa et al., (2011) stated that renal disease is usually initiated by glomerular and renovascular damage, whereas tubular affection progresses more slowly. Progression eventually results in generalized renal histological and functional changes affecting most renal structures leading to generalized progressive fibrosis and glomerulosclerosis.

Glomerular affection encountered in the present study could result from chemical or mechanical damage of glomeruli by the drug toxins. The glomerular filtration barrier becomes altered as regards the selectivity and permissivity and the glomerulus collapses leading to sclerosis and scarring with consequently reduced glomerular filtration (LópezNovoa et al., 2010). The extent of glomerular damage detected in the current work was further confirmed by histomorphometric analysis revealing a statistically significant decrease in the glomerular area in the higher-dose subgroups (IIc and IIe) compared to the control as well as to the lower-dose subgroups (IIb and IId).

In summary, the present work revealed that liver transaminases (AST and ALT) and LDH were significantly elevated in both the acute and subchronic studies, in response to both drugs. Cholesterol level showed significant elevation only in subchronic study in both doses of pimozide but not after thioridazine.

Kidney function tests (urea and creatinine) were significantly elevated in the subchronic study only in response to the high doses of both drugs.

No histological abnormalities were encountered in sections of rats treated with a single oral toxic dose of thioridazine in the acute study.

Insult resulting from acute pimozide targeted mainly blood vessels, sparing the other organ structures, manifested by congestion of blood vessels in liver, kidney and heart.

Subchronic study with lower lethal dose of thioridazine spared the liver and heart and only the kidney showed morphological abnormalities.

Using the higher lethal dose of thioridazine as well as both doses of pimozide induced marked morphological alterations.

\section{Conclusion and recommendations}

The anti-psychotic drugs tested in the current work proved to have definite toxic effects in case of acute and subchronic intake on the liver, kidney and heart. However, pimozide had more injurious and toxic effects than the other anti-psychotic drug thioridazine.

Thus, thioridazine or pimozide should be prescribed under restricted conditions and should be committed to the therapeutic doses with regular follow up of patients using these drugs and periodic assessment of cardiac, hepatic and renal functions should be done in those patients to detect early toxic effects.

\section{Acknowledgment}

We thank the central laboratories in Faculty of Agriculture-Cairo University for performing the biochemical studies.

\section{References}

Abernathy DR and Flockhart DA (2000): Molecular basis of cardiovascular drug metabolism: Implications for predicting clinically important drug interactions. Circulation, 101: 1749-54.

Amaral L, Boeree MJ, Gillespie SH et al., (2010): Thioridazine cures extensively drug-resistant tuberculosis (XDR-TB) and the need for global trials is now! Int. J. Antimicrob. Agents; 35 (6): 524-6.

Armitage P and Berry, G (1994): Medical Reseach; 3rd ed., Blackwell scientific publications, London, pp. 12-48.

Arrese M, Ananth M and Suchy FJ (1998): Hepatobiliary transport: Molecular mechanisms of development and cholestasis. Pediatr.Res., 44: 141-147.

Bancroft JD and Stevens A (1996): Theory and practice of histological techniques; $4^{\text {th }}$ ed., Churchill Livingstone, Edinburgh, pp. 147150.

Baptisa T, Baptista EA, Ying Kin NM et al., (2005): Antipsychotic side effects are different in men and women, Journal of Clinical Psychopharmacol., 6: 521-526.

Bergmeyer A (1986): A method for rapid determination of alkaline phosphatase, SGOT, SGPT. J. Biol. Chem., 164: 321-30.

Bouman WP and Pinner G (2002): Use of atypical antipsychotic drugs in old age psychiatry. Advances in Psychiatric Treatment; 8: 49-58.

Caraway W (1955): Determination of uric acid in serum. colourimetric method. Am. J. Clin. Path.; 25: 840-45.

Challoner K (2005): Toxicity of neuroleptic agents: In Victorian institute of forensic medicine; The Institute, pp. 59-63.

DeRoos FJ (2001): Neuroleptics In: Ford MD., Delaney KA., Lung LJ. and Erickson T. (eds.), Clinical Toxicology, Saunders Company, Philadelphia, pp. 539-545.

Drolet B, Rousseau G, Daleau P et al., (2001): Pimozide (Orap) prolongs cardiac repolarization by blocking the rapid component of the delayed rectifier potassium current in native cardiac myocytes.J Cardiovasc Pharmacol Ther. 6 (3): 255-60

Faulkner WR and King JW (1976): fundamentals of clinical chemistry; $2^{\text {nd }}$ ed., Saunders company, Philadelphia, pp. 994-998. 
Geerts A (2001): History,heterogenicity, developmental biology and functions of quiescent hepatic steellate cells. Semin Liver Dis.; 21(3): 311-335.

Giallourakis CC, Rosenberg PM and Friedman LS (2002): The liver in heart failure. Clin Liver Dis.; 6 (4): 947-67.

Giannini EG, Testa R and Savarino V (2005): Liver enzyme alteration: A guide for clinicians. CMAJ; 172: 367-79.

Goicoechea M, de Vinuesa SG, Verdalles U et al., (2010): Effect of allopurinol in chronic kidney disease progression and cardiovascular risk. Clin. J. Am. Soc. Nephrol.; 5:1388-1393.

Haddad LM, Shannon MW and Winchester JF (1998): Clinical Management of Poisoning and Drug Overdose; $3^{\text {rd }}$ ed., WB. Saunders Company, Philadelphia, pp. 572-588.

Healy D (2005): Psychiatric Drugs Explained; 4th ed., Churchill Livingstone, London, pp. 8-17.

Herak Kramberger CM and Sabolic I (2001): The integrity of renal cortical brush-border and basolateral membrane vesicles is damaged in vitro by nephrotoxic heavy metals. Toxicology; 156(2-3):139-47.

Jonathan MM and Carol EK (2004): The effects of antipsychotic therapy on serum lipids: a comprehensive review. Schizophrenia Research; 70(1): 1-17.

Kakar S, Kamath PS and Burgart LJ (2004): Sinusoidal dilatation and congestion in liver biopsy: is it always due to venous outflow impairment? Arch Pathol Lab Med.; 128(8):901-4.

Kang J, Chen XL and Rampe D (2001): The antipsychotic drugs sertindole and pimozide block erg3, a human brain $\mathrm{K}( \pm$ ) channel. Biochem. Biophys. Res. Commun.; 286(3):499-504.

Kang J, Wang L, Cai F et al., (2000): High affinity blockade of the HERG cardiac $\mathrm{K}( \pm)$ channel by the neuroleptic pimozide. Eur J Pharmacol; 392(3):137-140.

Kasckow J, Felmet $\mathrm{K}$ and Zisook S (2011): Managing suicide risk in patients with schizophrenia. CNS Drugs; 25(2):129-43.

Kiernan, JA, (2001): Histological and histochemical methods: theory and practice; $3 \mathrm{rd}$ ed., Arnold publisher, London, pp. 111-162.

Klaassen CD (2001): Casarett and Doull's Toxicology: The Basic Science of Poisons; $6^{\text {th }}$ ed., McGraw-Hill Companies, New York, pp. 567-587.

Kristiana I, Sharpe LJ, Catts VS et al., (2010): Antipsychotic drugs upregulate lipogenic gene expression by disrupting intracellular trafficking of lipoprotein-derived cholesterol. Pharmacogenomics J.; 10(5): 396-407.

Leishi K, Nomura M, Kawano T et al., (2007): The effect of G-CSF in a myocardial ischemia reperfusion model rat. J. Med. Invest.; 54: 177-183.
Lieberman AJ and Tasman A, (2006): Handbook of psychiatric drugs; $1^{\text {st }}$ ed., John Wiley and Sons, West Sussex, pp:1-7.

López-Novoa JM, Martínez-Salgado C, RodríguezPeña AB et al., (2010): Common pathophysiological mechanisms of chronic kidney disease: Therapeutic perspectives. Pharmacol Ther.; 128:61-81.

López-Novoa JM, Rodríguez-Peña AB, Ortiz A et al., (2011): Etiopathology of chronic tubular, glomerular and renovascular nephropathies: Clinical implications. Journal of Translational Medicine; 9:13-23.

Milnes JT, Witchel HJ, Leaney JL et al., (2006): hERG $\mathrm{K}+$ channel blockade by the antipsychotic drug thioridazine: An obligatory role for the S6 helix residue F656. Biochem Biophys Res Commun.; 351(1):273-80.

Moffat CA, Osselton MD, Widdop R et al., (2004): Clarke's Analysis of Drugs and Poisons: In Pharmaceuticals, Body Fluids and Postmortem Material; $3^{\text {rd }}$ ed., Pharmaceutical Press, London, pp. 643-669.

Moore NA. (1999): Behavioural pharmacology of the new generation of antipsychotic agents [Review]. Br. J. Psychiatr. ; 38: 5-11.

Naschitz JE, Slobodin G, Lewis RJ et al., (2000): Heart diseases affecting the liver and liver diseases affecting the heart. Am Heart J.; 140: 111-20.

Nony PA and Schnellmann RG (2001): Interactions between collagen IV and collagen-binding integrins in renal cell repair after sublethal injury. Mol Pharmacol.; 60:1226-34.

Patton CJ and Crouch SR (1977): Enzymatic method for estimation of plasma urea. J. Anal. Chem. 49: 446-69.

Peluso MJ, Lewis SW, Barnes TR et al., (2012): Extrapyramidal motor side-effects of first- and second-generation antipsychotic drugs. $\mathrm{Br} \mathrm{J}$ Psychiatry. 200:387-92.

Raedler TJ. (2010): Cardiovascular aspects of antipsychotics. Curr Opin Psychiatry.;(6):57481.

Ramot Y and Nyska A (2007): Drug-Induced Thrombosis-Experimental, Clinical, and Mechanistic Considerations. Toxicol Pathol.; 35(2): 208-25.

Rao SP, Miller S, Rosenbaum R et al., (1999): "Cardiac troponin I and cardiac enzymes after electrophysiologic studies, ablations, and defibrillator implantations". Am. J. Cardiol.; 84 (4): 470, A9.

Richmond W. (1973): Enzyme preparation for cholesterol investigations. J.Clin. Chem.; 19: 1350-55.

Sadock JB, Kaplan IH and Sadock VA (2004): Kaplan and Sadock's synopsis of Psychiatry Behavioral Sciences and Clinical Psychiatry; $9^{\text {th }}$ ed., Lippincott Williams and Wilkins, USA, pp 589-610. 
Schonwald S (2001): Medical Toxicology A Synopsis and Study Guide; Lippincott, Williams and Wilkins, Philadelphia, pp. 333-353.

Sinkiewicz W, Balak W, Fares I et al., (2006): Polymorphic ventricular tachycardia of torsade de pointes type in patient with schizophrenia treated with thioridazine. Pol Arch Med Wewn. 116(6):1188-91.

Snively CS and Gutierrez C (2004): Chronic kidney disease: Prevention and treatment of chronic complications. American Family Physician; 70:1921-28.

Toubia N and Sanyal AJ (2008): Portal Hypertension and Variceal Hemorrhage. Med Clin N Am.; 92:551-74.

Tutor-Crespo MJ, Paz E, Hermida J et al., (2007): Renal tubular dysfunction in schizophrenic patients treated with antipsychoticdrugs. Clin Lab. 53(7-8): 433-8.
Voruganti LP, Baker LK and Awad AG (2008): New generation antipsychotic drugs and compliance behaviour. Current Opinion in Psychiatry; 21 (2): 133-9.

Wang PS, Schneeweiss S and Avorn J (2005): Risk of death in elderly users of conventional vs. atypical antipsychotic medications. N. Engl. J. Med.; 353 (22): 2335-41.

Weisshaar D, Gossrau E. and Fader LB (1975): Normal ranges of alpha-HBDH, $\mathrm{LDH}, \mathrm{AP}$, and LAP as measured with substrate optimated test charges. Med. We Lt., 26 (9): 387-92.

Whitaker R (2004): The case against antipsychotic drugs: a 50-year record of doing more harm than good". Medical Hypotheses 62 (1): 5-13.

Yoram B, Marnina S and Igor P (2005): Assessing cardiovascular risks of olanzepine treatment: a 6 month study versus haloperidol in schizophrenia patients. Intern. Clin. Psychopharmacol.; 20 (6):315-17.

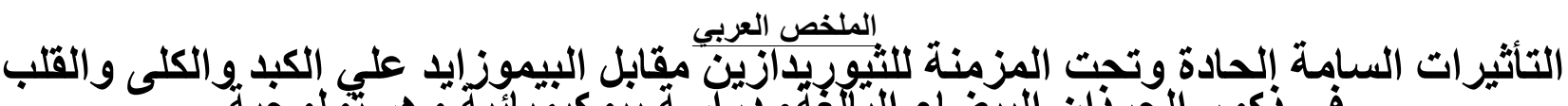

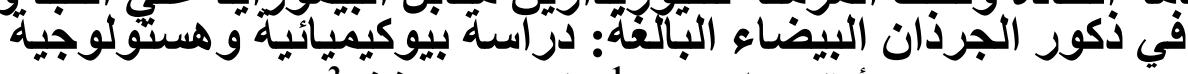

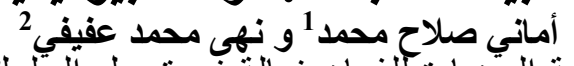

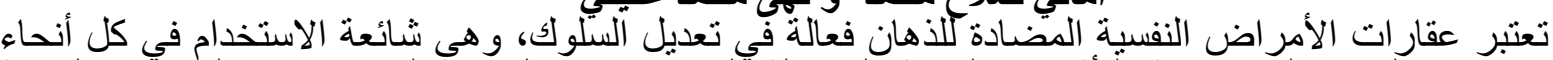

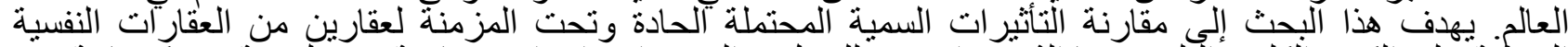

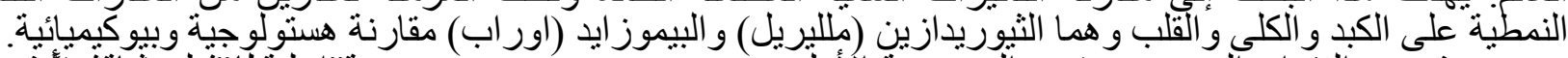

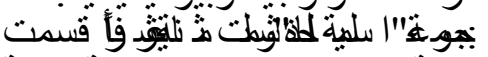

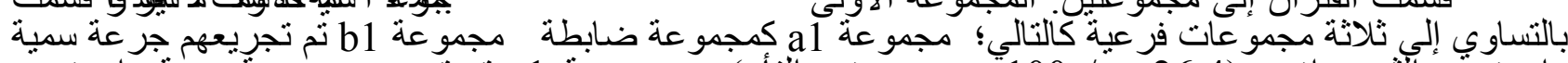

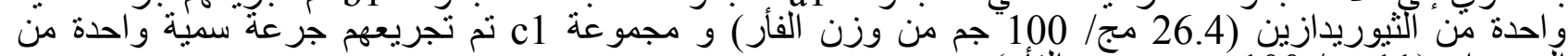

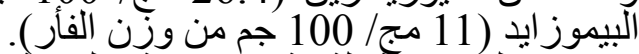

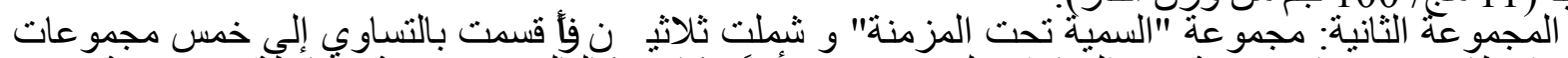

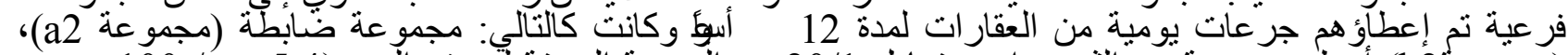

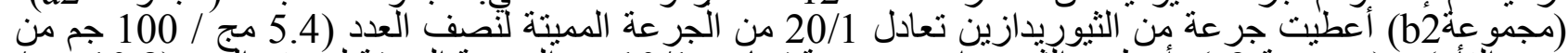

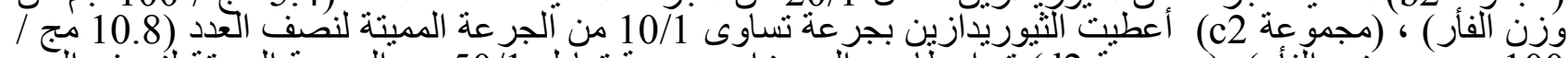

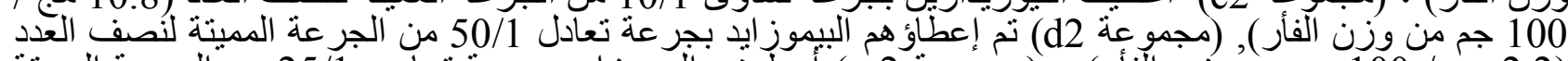

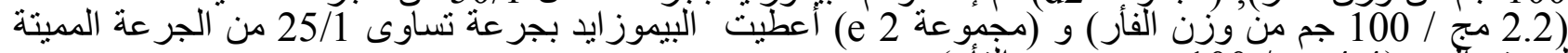

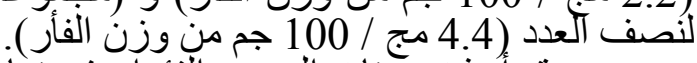

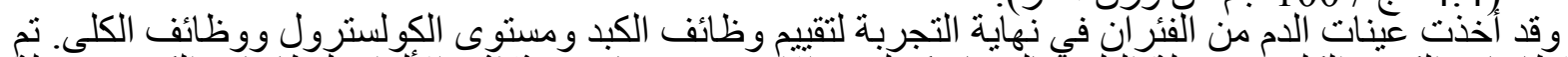

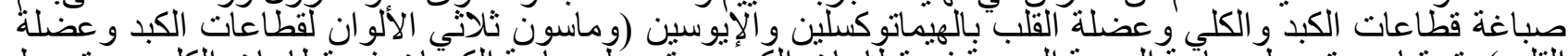

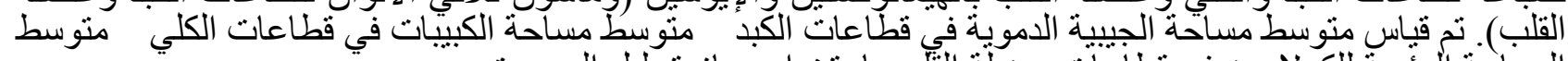

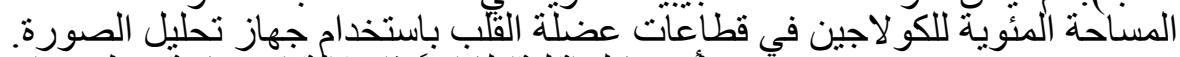

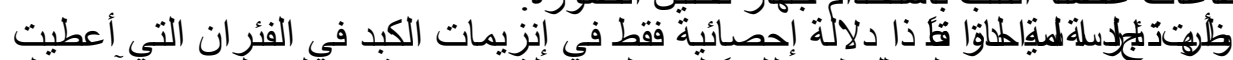

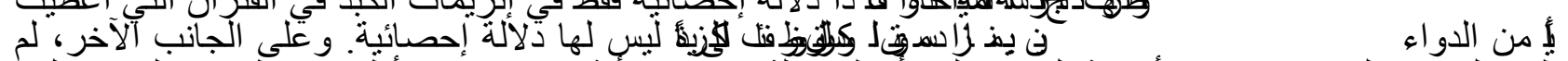

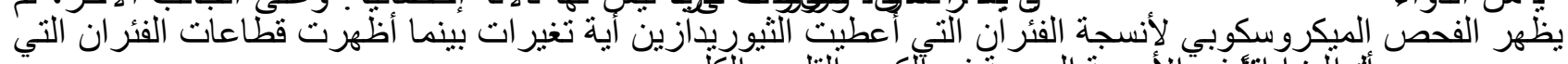

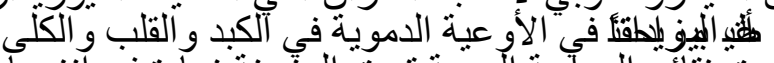

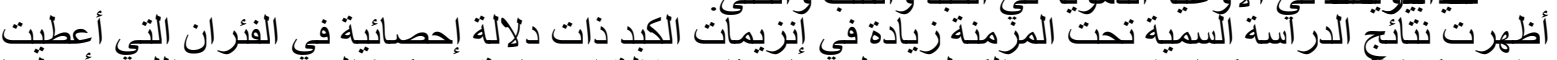

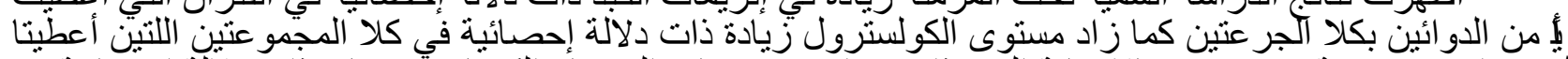

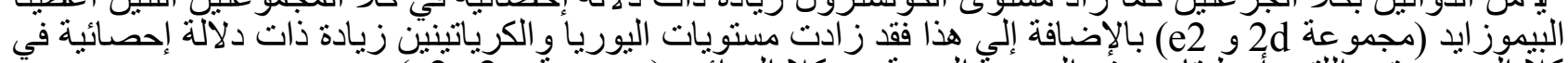

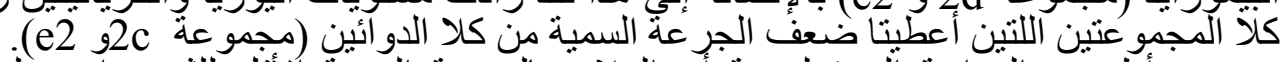

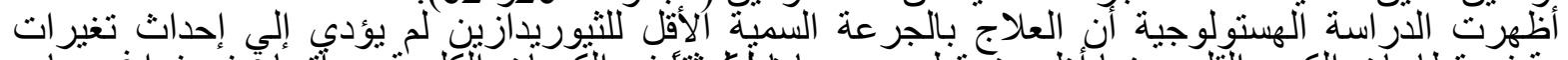

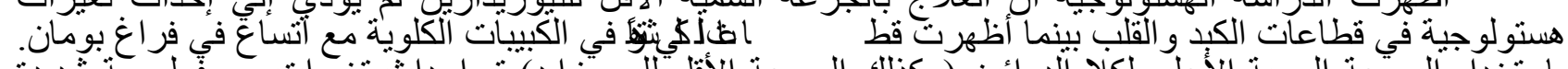

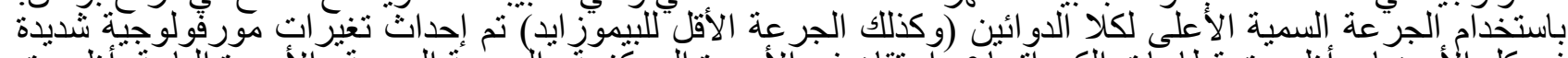

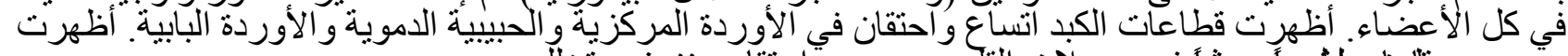

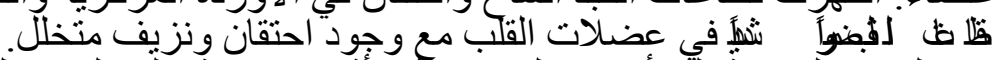

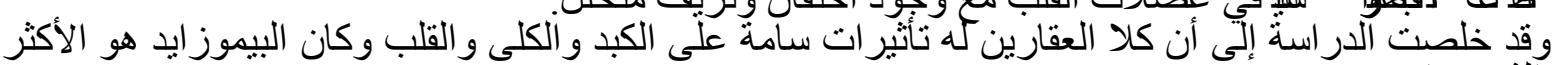

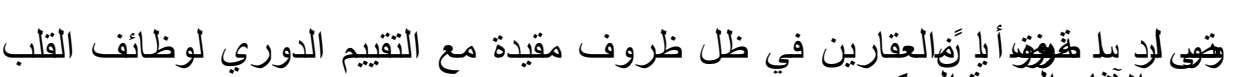
و الكبد و الكلى حتى يتسنى الكثف عن الآثار السمية المبكرة. 
2 قسم الهستولوجيا كلية الطب جامعة القاهرة 